\title{
A Systematic Study of the In Vitro Pharmacokinetics and Estimated Human In Vivo Clearance of Indole and Indazole-3-Carboxamide Synthetic Cannabinoid Receptor Agonists Detected on the Illicit Drug Market
}

\author{
Andrew M. Brandon ${ }^{1}$, Lysbeth H. Antonides ${ }^{1}$, Jennifer Riley ${ }^{2}$, Ola Epemolu ${ }^{2}$, Denise A. McKeown ${ }^{3}$, \\ Kevin D. Read ${ }^{2, *}$ and Craig McKenzie ${ }^{1, *}$ \\ check for \\ 1 Leverhulme Research Centre for Forensic Science, School of Science and Engineering, University of Dundee, \\ Dundee DD1 4HN, UK; a.m.brandon@dundee.ac.uk (A.M.B.); 1.h.antonides@dundee.ac.uk (L.H.A.) \\ 2 Drug Discovery Unit, Wellcome Centre for Anti-Infectives Research, School of Life Sciences, University of \\ Dundee, Dundee DD1 5EH, UK; j.y.riley@dundee.ac.uk (J.R.); r.epemolu@dundee.ac.uk (O.E.) \\ 3 Forensic Medicine and Science, School of Medicine, Dentistry and Nursing, College of Medical, Veterinary \\ and Life Sciences, University of Glasgow, Glasgow G12 8QQ, UK; Denise.McKeown@glasgow.ac.uk \\ * Correspondence: K.Read@dundee.ac.uk (K.D.R.); c.t.mckenzie@dundee.ac.uk (C.M.)
}

updates

Citation: Brandon, A.M.; Antonides, L.H.; Riley, J.; Epemolu, O.;

McKeown, D.A.; Read, K.D.;

McKenzie, C. A Systematic Study of the In Vitro Pharmacokinetics and Estimated Human In Vivo Clearance

of Indole and Indazole-3-Carboxamide Synthetic Cannabinoid Receptor Agonists Detected on the Illicit Drug Market. Molecules 2021, 26, 1396. https://doi.org/10.3390/ molecules 26051396

\section{Academic Editors: Mário Barroso,}

Eugenia Gallardo and

Luís Passarinha

Received: 18 January 2021

Accepted: 28 February 2021

Published: 5 March 2021

Publisher's Note: MDPI stays neutral with regard to jurisdictional claims in published maps and institutional affiliations.

Copyright: (c) 2021 by the authors. Licensee MDPI, Basel, Switzerland. This article is an open access article distributed under the terms and conditions of the Creative Commons Attribution (CC BY) license (https:/ / creativecommons.org/licenses/by/ $4.0 /)$.
Abstract: In vitro pharmacokinetic studies were conducted on enantiomer pairs of twelve valinate or tert-leucinate indole and indazole-3-carboxamide synthetic cannabinoid receptor agonists (SCRAs) detected on the illicit drug market to investigate their physicochemical parameters and structure-metabolism relationships (SMRs). Experimentally derived Log $\mathrm{D}_{7.4}$ ranged from 2.81 (AB-FUBINACA) to 4.95 (MDMB-4en-PINACA) and all SCRAs tested were highly protein bound, ranging from $88.9 \pm 0.49 \%$ ((R)-4F-MDMB-BINACA) to $99.5 \pm 0.08 \%$ ((S)-MDMB-FUBINACA). Most tested SCRAs were cleared rapidly in vitro in pooled human liver microsomes (pHLM) and pooled cryopreserved human hepatocytes (pHHeps). Intrinsic clearance $\left(\mathrm{CL}_{\text {int }}\right)$ ranged from $13.7 \pm 4.06$

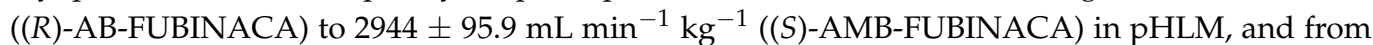
$110 \pm 34.5$ ((S)-AB-FUBINACA) to $3216 \pm 607 \mathrm{~mL} \mathrm{~min}^{-1} \mathrm{~kg}^{-1}((S)$-AMB-FUBINACA) in pHHeps. Predicted Human in vivo hepatic clearance $\left(\mathrm{CL}_{\mathrm{H}}\right)$ ranged from $0.34 \pm 0.09((S)$-AB-FUBINACA) to $17.79 \pm 0.20 \mathrm{~mL} \mathrm{~min}{ }^{-1} \mathrm{~kg}^{-1}((S)$-5F-AMB-PINACA) in pHLM and $1.39 \pm 0.27$ ((S)-MDMBFUBINACA) to $18.25 \pm 0.12 \mathrm{~mL} \mathrm{~min}^{-1} \mathrm{~kg}^{-1}((S)-5 \mathrm{~F}-\mathrm{AMB}-\mathrm{PINACA})$ in pHHeps. Valinate and tert-leucinate indole and indazole-3-carboxamide SCRAs are often rapidly metabolised in vitro but are highly protein bound in vivo and therefore predicted in vivo $C L_{H}$ is much slower than $C L_{\text {int }}$. This is likely to give rise to longer detection windows of these substances and their metabolites in urine, possibly as a result of accumulation of parent drug in lipid-rich tissues, with redistribution into the circulatory system and subsequent metabolism.

Keywords: new psychoactive substances; synthetic cannabinoid receptor agonists; in vitro metabolism; in vivo prediction; pharmacokinetics

\section{Introduction}

Synthetic cannabinoid receptor agonists (SCRAs) are a diverse group of new psychoactive substances (NPS) that bind to, and activate, human cannabinoid receptors $\left(\mathrm{CB}_{1}\right.$ and $\mathrm{CB}_{2}$ ) [1,2]. More than 200 of these compounds have been reported on the illicit market to date $[3,4]$. SCRA intoxications have been linked to a variety of adverse effects and have been implicated in drug intoxication and drug death cases worldwide [5,6]. The exact mechanisms of many of their harmful effects remain unclear, although some, at least, are mediated via the $\mathrm{CB}_{1}$ receptor [7-11]. The intensity and duration of the physiological and psychoactive effects experienced by users of SCRAs will be influenced by their pharmacodynamics and pharmacokinetics, as well as other factors such as the dose, presence 
of co-ingested substances and individual factors such as sex and underlying health status [11]. Commonly, the actual drug present and its concentration in a preparation will be unknown to the user. Pharmacokinetics and pharmacodynamics will vary between SCRA structural classes [12-21], being influenced by physicochemical properties related to structural features.

The chemical structures of the SCRAs discussed in this study, including a representation showing the four constituent structural subunits (head, linker, core, tail), are provided in Figure 1 and are referred to by numbers in bold in parenthesis throughout the text. Amongst the most prevalent and potent SCRAs are the valinate and tert-leucinate indole and indazole-3-carboxamides. These include AMB-FUBINACA (1) (MMB-FUBINACA; methyl [1-(4-fluorobenzyl)-1H-indazole-3-carbonyl]valinate), 5F-MDMB-PINACA (2) (5FADB; methyl 2-[1-(5-fluoropentyl)-1H-indazole-3-carboxamido]-3,3-dimethylbutanoate), 5F-MDMB-PICA (3) (methyl 2-[1-(5-fluoropentyl)-1H-indole-3-carboxamido]-3,3dimethylbutanoate), 4F-MDMB-BINACA (4) (4F-ADB, 4F-MDMB-BUTINACA; methyl 2-[1-(4-fluorobutyl)-1H-indazole-3-carboxamido]-3,3-dimethylbutanoate) and MDMB-4enPINACA (5) (5-CL-ADB-A; methyl 3,3-dimethyl-2-[1-(pent-4-en-1-yl)-1H-indazole-3carboxamido] butanoate) [22-25].

SCRAs have been detected on the illicit market as pure substances, but are more commonly detected following infusion into herbal materials, papers and e-liquids for smoking and vaping [22,26-28]. Valinate and tert-leucinate indole and indazole-3-carboxamide SCRAs are chiral compounds, and in all SCRAs studied to date, the (S)-enantiomer is significantly more potent than the $(R)$-enantiomer. Chiral profiling data indicate that the SCRAs detected in the majority of samples tested are essentially enantiopure (S)-enantiomer however the presence of up to $16 \%(R)$-enantiomer has been reported in a small number of cases [1,29-31].

An understanding of the physicochemical parameters underpinning the behavior of SCRAs in biological systems, their pharmacokinetics and their effects is essential. For example, the proportion of the SCRA dose that is not plasma protein-bound (the free drug) will be responsible for the drug's pharmacological effects. This unbound fraction will also be available for metabolism by hepatic and, potentially, extrahepatic enzymes. Whilst a great deal is known about the pharmacokinetics of naturally occurring cannabinoids such as $\Delta$ 9-tetrahydrocannabinol (THC) [32-36] and its metabolites, less is known about the pharmacokinetics of the valinate and tert-leucinate indole and indazole-3-carboxamide SCRAs [37-39]. Like SCRAs, the most common routes of administration of THC are smoking and vaping. THC is more bioavailable via inhalation compared to ingestion, and inhalation avoids first-pass metabolism leading to rapid onset of psychoactive effects [34,36]; is highly lipophilic $(\log P=6.7$ [39]) and has a low distribution into erythrocytes and a high plasma protein affinity (95-99\% protein-bound in plasma) [33]. Synthetic cannabinoids are also lipophilic, with theoretical $\log \mathrm{P}$ values in the literature ranging from 3.02-8.14 [18-21], although theoretical $\log P$ values reported for the valinate and tert-leucinate indole-/indazole-3-carboxamides indicate that they are amongst the least lipophilic of the SCRAs.

THC is distributed into the adipose tissue, especially in chronic users, with subsequent slow release from the adipose leading to long detection windows for THC and its metabolites [33,36,40]. Many SCRAs are also highly lipophilic; JWH-210 (4-ethylnaphthalen1-yl-(1-pentylindol-3-yl)methanone) (log P = 7.5) and RCS-4 (2-(4-methoxyphenyl)-1-(1pentyl-indol-3-yl)methanone) ( $\log \mathrm{P}=5.6)$ have shown similar distribution to THC into the adipose tissue of experimentally exposed pigs [39], and long detection windows for other SCRAs in humans have also been reported [41-43]. However, lipophilicity is not the only determining factor for uptake by adipocytes [39], as some highly lipophilic drugs are not extensively distributed into adipose tissue $[44,45]$ and structural features are also thought to contribute $[46,47]$. 

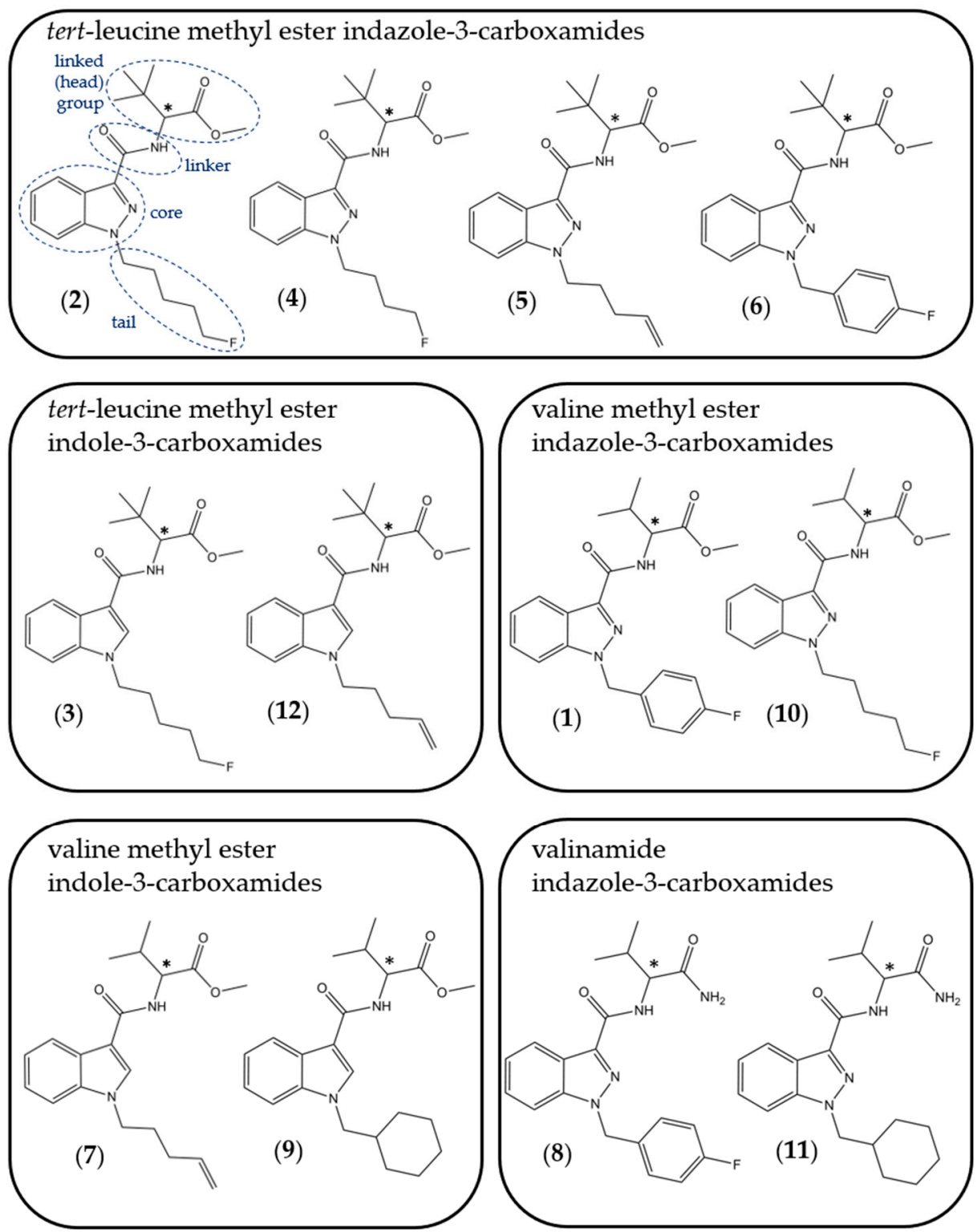

Figure 1. Structures of synthetic cannabinoid receptor agonists (SCRAs) involved in this study. (1) AMB-FUBINACA; (2) 5F-MDMB-PINACA; (3) 5F-MDMB-PICA; (4) 4F-MDMB-BINACA; (5) MDMB-4en-PINACA; (6) MDMB-FUBINACA; (7) AMB-4en-PICA; (8) AB-FUBINACA; (9) AMBCHMICA; (10) 5F-AMB-PINACA; (11) AB-CHMINACA; (12) MDMB-4en-PICA. Asterisk $\left(^{*}\right)$ indicates chiral centre. Numbering used in the Figure reflects the order in which structures are mentioned in the text.

Castaneto et al. (2015) provided a thorough review of the pharmacokinetics of earlier emerging SCRAs [12]; however, limited/estimated human in vivo pharmacokinetic data are available for currently prevalent SCRAs. The available data from in vivo pharmacokinetic studies for valinate and tert-leucinate indole-/indazole-3-carboxamides are based either on long-term abstinence monitoring in casework from users reported to have smoked or vaped the substances and then abstained from their use [43], or on small scale self-administration studies where the drug is ingested rather than smoked or vaped and this does not reflect user behaviour or chronic use [43,48-50].

Our understanding of the structure-activity relationships (SARs) and structuremetabolism relationships (SMRs) of the valinate and tert-leucinate indole and indazole-3carboxamide SCRAs is increasing, and phase I metabolite formation is well characterised in vitro $[1,2,18,23,31,37,38,51-55]$. A valuable systematic study of the SMRs of valinate and 
tert-leucinate indole- and indazole-3-carboxamide SCRAs using pHLM has recently been published [37]. In SCRAs where a valine (dimethyl) methyl ester (AMB-) head group is present, the most abundant metabolite formed is the carboxylic acid metabolite; where a tertleucine (trimethyl) methyl ester (MDMB-) head group is present the carboxylic acid metabolite is formed but is rarely the most abundant metabolite in vitro (MDMB-FUBINACA (6) (methyl 2-[1-(5-fluoropentyl)- $1 H$-indazole-3-carboxamido]-3,3-dimethylbutanoate) is an exception, probably due to the metabolic stability of the fluorobenzyl moiety). Where a valinamide (dimethyl) (AB-) head group is present, the carboxylic acid metabolite is formed to a greater extent when an indazole core is also present, compared to an indole core, but is never the principal metabolite. Where a tert-leucinamide (trimethyl) (ADB-) head group is present the carboxylic acid metabolite is only ever a minor metabolite in vitro, with the most prevalent metabolite determined by the relative lability of the other structural features present [37]. Oxidative defluorination of 5F-MDMB-PINACA (2), forming a major metabolite in vitro and in vivo, has been shown to occur in HLM without the presence of $\mathrm{NADPH}$, suggesting the involvement of non-CYP enzymes [54]. The phase I metabolism of 4F-MDMB-BINACA (4) has recently been described [55] and was found to involve several cytochrome P450 and human carboxylesterase 1 (CES-1) isoforms, with the carboxylic acid metabolite and formation of a lactone among the most abundant metabolites.

Recently, valinate and tert-leucinate indole and indazole-3-carboxamide SCRAs with alkene 'tail' groups (MDMB-4en-PINACA (5) and AMB-4en-PICA (7) (MMB-4en-PICA, MMB-022; methyl 3-methyl-2-[(1-pent-4-enylindole-3-carbonyl)amino] butanoate)) have been detected on the illicit market and in toxicological samples [56,57]. Metabolite identification studies of such SCRAs and other drugs containing an alkene moiety have demonstrated the in vitro formation of a dihydrodiol metabolite (via epoxidation catalysed by CYP isoenzymes, followed by hydration of the epoxide likely facilitated by CYP enzymes and epoxide hydrolase $[56,58,59])$, and specifically for SCRAs the formation of the carboxylic acid metabolite (through ester hydrolysis), and a carboxylic acid with dihydrodiol metabolite [56]. The carboxylic acid metabolite of MDMB-4en-PINACA (5) was the only metabolite detected in blood taken for toxicological analysis from an authentic user, whilst both the carboxylic acid and carboxylic acid with dihydrodiol metabolites were detected in urine. Studies have shown that the carboxylic acids are formed in vitro without the presence of NADPH $[54,60,61]$, and their hepatic formation is thought to be mediated by carboxylesterases, principally CES-1 [55,61,62]. However, interpretation of the detection of carboxylic acid metabolites in plasma in isolation, formed by hydrolysis of the methyl ester and amide moieties, should be treated cautiously. Some SCRAs have been shown to be unstable in human blood when samples have not been frozen prior to analysis [63-65], and carboxylesterases are not present in human blood [66,67]. The presence of the carboxylic acid metabolites of these and similar SCRAs in blood could therefore be explained, at least in part, by non-enzymatic hydrolysis or by the action of other plasma esterases prior to, or during, storage, rather than as a result of the recirculation of Phase I metabolites in the body after formation, primarily in the liver $[64,67,68]$.

This study aims to increase understanding of the factors influencing the metabolism and pharmacokinetics of valinate or tert-leucinate indole- and indazole-3-carboxamide SCRAs. Their lipophilicity (Log P/Log $\mathrm{D}_{7 \cdot 4}$ ) was determined using both in silico methods and experimentally; their short-term stability in plasma has been assessed in vitro under physiological conditions; and their plasma protein binding (PPB) values were determined experimentally for the first time. In vitro intrinsic clearance was calculated following incubation with pooled human liver microsomes (pHLM) and pooled human cryopreserved hepatocytes (pHHeps) for 12 SCRA enantiomer pairs, to investigate the structural and conformational features influencing their interaction with metabolic enzymes and their metabolic clearance rates. In vitro pharmacokinetic data were then used to estimate in vivo human hepatic clearance and hepatic extraction ratios, thus helping to predict their pharmacokinetics in a manner relevant to toxicological casework. 


\section{Results and Discussion}

\subsection{Lipophilicity}

Theoretical $\log \mathrm{P}$ values were calculated for the 12 SCRAs included in this study (Figure 1) using a range of software packages (see Section 3 for details), and the chromatographic hydrophobicity index (CHI) $\log \mathrm{D}$ at $\mathrm{pH} 7.4\left(\log \mathrm{D}_{7.4}\right)$ was determined experimentally for each (S)-enantiomer for comparison. As the tested SCRAs are nonionizable, $\log \mathrm{P}$ and $\log \mathrm{D}_{7.4}$ are equivalent. Although predicted values varied between in silico prediction packages, the ranking of compounds was comparable. AB-FUBINACA (8) (N-(1-amino-3-methyl-1-oxobutan-2-yl)-1-(4-fluorobenzyl)-1H-indazole-3-carboxamide) was the least lipophilic SCRA tested (Log P range = 2.66-3.24) with AMB-CHMICA (9) (methyl [1-(cyclohexylmethyl)-1H-indole-3-carbonyl]valinate) the most lipophilic (Log $P$ range $=3.84-5.51)($ Table 1$)$. The predicted data are similar to previously reported in silico data for valinate and tert-leucinate indole and indazole-3-carboxamide SCRAs (2.29-3.81) [19], calculated using ChemBioDraw (Cambridge Soft Corporation, Cambridge, MA, USA).

Table 1. Predicted Log P and experimentally derived Log $D_{7.4}$ values for test SCRAs calculated using a chromatographic hydrophobicity index (CHI). SwissADME data are shown, with log P ranges obtained using Gastroplus, MoKa, Canvas and X $\log P$ software provided for comparison (see Section S2 of the supplementary information for full data set). Data for the azaindole-3-carboxamide SCRA, 5F-AB-P7AICA are shown for comparative purposes.

\begin{tabular}{cccc}
\hline Compound & Experimental Log $\mathbf{D}_{\mathbf{7 . 4}}$ & $\begin{array}{c}\text { SwissADME Predicted } \\
\text { Log P }\end{array}$ & $\begin{array}{c}\text { Log P Range from Other Software } \\
\text { Packages }\end{array}$ \\
\hline MDMB-4en-PINACA (5) & 4.95 & 3.41 & $3.61-4.00$ \\
AMB-CHMICA (9) & 4.77 & 3.84 & $4.30-5.51$ \\
MDMB-FUBINACA (6) & 4.69 & 3.83 & $4.08-4.24$ \\
5F-MDMB-PINACA (2) & 4.50 & 3.63 & $3.76-3.90$ \\
MDMB-4en-PICA (12) & 4.40 & 3.77 & $3.98-4.98$ \\
AMB-FUBINACA (1) & 4.28 & 3.50 & $3.75-4.09$ \\
4F-MDMB-BINACA (4) & 4.18 & 3.39 & $3.33-3.40$ \\
5F-AMB-PINACA (10) & 4.07 & 3.41 & $3.31-3.64$ \\
5F-MDMB-PICA (3) & 4.06 & 3.98 & $4.10-4.90$ \\
AMB-4en-PICA (7) & 3.97 & 3.53 & $3.50-4.83$ \\
AB-CHMINACA (11) & 3.71 & 2.91 & $3.10-3.55$ \\
AB-FUBINACA (8) & 2.81 & 2.80 & $2.66-3.24$ \\
5F-AB-P7AICA & - & 2.45 & $1.57-2.74$ \\
\hline
\end{tabular}

Experimental $\log \mathrm{D}_{7.4}$ values (Table 1) ranged from 2.81 (AB-FUBINACA (8)) to 4.95 (MDMB-4en-PINACA (5)). Theoretical log P values for SCRAs with an indole core were consistently higher than those with an indazole core. However, this was not the case with the experimentally derived data. Predictions were in the closest agreement for 5FMDMB-PICA (3) and AB-FUBINACA (8). For all other compounds, experimental values were generally under-predicted by in silico methods. With the exception of MDMB-4enPINACA (5), which was the most lipophilic SCRA studied according to experimental data, all predicted values were within one log unit of experimental values.

It has been reported that it may not be possible to detect parent SCRAs with a log P of 4-5 or greater in urine [19]. The majority of parent valinate and tert-leucinate indole and indazole-3-carboxamide SCRAs in this study have $\log \mathrm{P}$ or $\log \mathrm{D}$ values at or below this range; they have often been detected in urine, but usually as a very small proportion compared to their metabolites [43,64,69-73]. However, a recent study, involving the oral consumption of the 7-azaindole valinamide-based SCRA, 5F-AB-P7AICA, unusually identified the parent compound as the major component present in urine [50]. Although not included in this study, this SCRA was estimated to have an average theoretical $\log \mathrm{P}$ value of $2.15 \pm 0.46$ (Table 1 ) and so was the least lipophilic molecule measured. This may explain why the parent drug is detected in urine at a higher proportion than its metabolites. 
In addition, it has been postulated that the presence of an azaindole core structure may decrease the extent to which metabolism occurs at other sites on the structure [50].

\subsection{Plasma Stability Studies}

The instability of valinate and tert-leucinate indole and indazole-3-carboxamide SCRAs in unfrozen whole blood and plasma samples has been reported previously $[37,38,63]$, whilst other somewhat contradictory reports have shown long-term stability for some analogs (315 days) at temperatures of up to $20^{\circ} \mathrm{C}$ in human plasma [65]. The stability of the majority of the SCRAs described in this study in pooled human plasma (some $(R)$-enantiomers were not tested) over three to five hours under physiological conditions $\left(37^{\circ} \mathrm{C}, \mathrm{pH} 7.4\right)$ was assessed prior to carrying out the five-hour long PPB studies. Procaine, the positive control, had a half-life of 6.5 min with no esterase inhibitors present, in line with other reports and the values expected in our laboratory $[74,75]$, and was stable when plasma was pre-incubated with esterase inhibitors.

Over $85 \%$ of the parent compound remained following three hours of incubation (Table 2 and Figure 2, with figures for all compounds studied shown in Section S5 of the supplementary information).

No structure-stability relationship was observed, there was no difference in the stability between enantiomers, and there was no substantial difference between the incubations with or without inhibitors over the three-hour stability study. The plasma stability of $(S)$ AMB-FUBINACA (1) was tested for five hours, the time used in this study for PPB studies, due to its previously reported instability in casework [63]. After five hours, $94 \pm 0.1 \%$ $(n=3)$ of the compound remained when incubated with esterase inhibitors, and $86 \pm 4.0 \%$ $(n=4)$ when incubated without esterase inhibitors. This suggests that AMB-FUBINACA may be degraded by plasma esterases over extended time periods, however further study using a longer plasma incubation time is required.

Table 2. Short-term plasma stability of tested SCRAs and positive control (procaine). ${ }^{a}$ indicates data for $5 \mathrm{~h}$ incubations.

\begin{tabular}{|c|c|c|c|c|}
\hline \multirow[t]{2}{*}{ Compound } & \multicolumn{4}{|c|}{$\begin{array}{l}\text { Parent Compound Remaining (\%) } \\
\qquad\left(3 \mathrm{~h}^{\mathrm{a}} 5 \mathrm{~h}\right)\end{array}$} \\
\hline & No Esterase Inhibitors & $n=$ & Esterase Inhibitors & $n=$ \\
\hline Procaine (control) & $0.03 \pm 0.02 ;^{\mathrm{a}} 0.08 \pm 0.11$ & 5 & $98.3 \pm 8.0 ;^{\text {a }} 91.0 \pm 1.7$ & 5 \\
\hline (S)-AB-FUBINACA (8) & $104.4 \pm 1.1$ & 3 & $102.7 \pm 2.5$ & 3 \\
\hline (S)-AB-CHMINACA (11) & $98.2 \pm 7.2$ & 3 & $97.9 \pm 7.0$ & 3 \\
\hline$(S)$-5F-MDMB-PICA (3) & $97.3 \pm 6.4$ & 3 & $99.5 \pm 5.8$ & 3 \\
\hline (R)-5F-MDMB-PICA (3) & $103.2 \pm 14.5$ & 3 & $97.7 \pm 5.6$ & 3 \\
\hline (S)-AMB-FUBINACA (1) & $96.6 \pm 3.8 ;^{\text {a }} 85.9 \pm 4.0$ & 4 & $96.1 \pm 1.6 ;^{\text {a }} 93.5 \pm 0.1$ & 3 \\
\hline (S)-MDMB-4en-PINACA (5) & $94.8 \pm 0.7$ & 3 & $89.0 \pm 3.3$ & 3 \\
\hline (R)-MDMB-4en-PINACA (5) & $87.2 \pm 6.9$ & 3 & $89.4 \pm 3.4$ & 3 \\
\hline (S)-MDMB-FUBINACA (6) & $94.2 \pm 6.3$ & 3 & $91.6 \pm 2.2$ & 3 \\
\hline (S)-AMB-CHMICA (9) & $93.9 \pm 9.3$ & 3 & $90.5 \pm 3.4$ & 3 \\
\hline (S)-4F-MDMB-BINACA (4) & $93.1 \pm 5.1$ & 3 & $96.0 \pm 2.9$ & 3 \\
\hline (R)-4F-MDMB-BINACA (4) & $91.1 \pm 6.8$ & 3 & $96.0 \pm 1.7$ & 3 \\
\hline (S)-5F-AMB-PINACA (10) & $93.0 \pm 6.1$ & 3 & $89.8 \pm 1.5$ & 3 \\
\hline (S)-AMB-4en-PICA (7) & $92.6 \pm 8.3$ & 3 & $95.6 \pm 6.8$ & 3 \\
\hline (R)-AMB-4en-PICA (7) & $91.7 \pm 1.9$ & 3 & $95.5 \pm 2.9$ & 3 \\
\hline (S)-5F-MDMB-PINACA (2) & $92.5 \pm 10.2$ & 7 & $97.0 \pm 1.1$ & 3 \\
\hline (R)-5F-MDMB-PINACA (2) & $95.9 \pm 6.7$ & 6 & $100.1 \pm 7.0$ & 7 \\
\hline$(S)$-MDMB-4en-PICA (12) & $91.5 \pm 8.6$ & 3 & $89.4 \pm 2.3$ & 3 \\
\hline (R)-MDMB-4en-PICA (12) & $90.3 \pm 5.4$ & 3 & $87.7 \pm 11.0$ & 3 \\
\hline
\end{tabular}



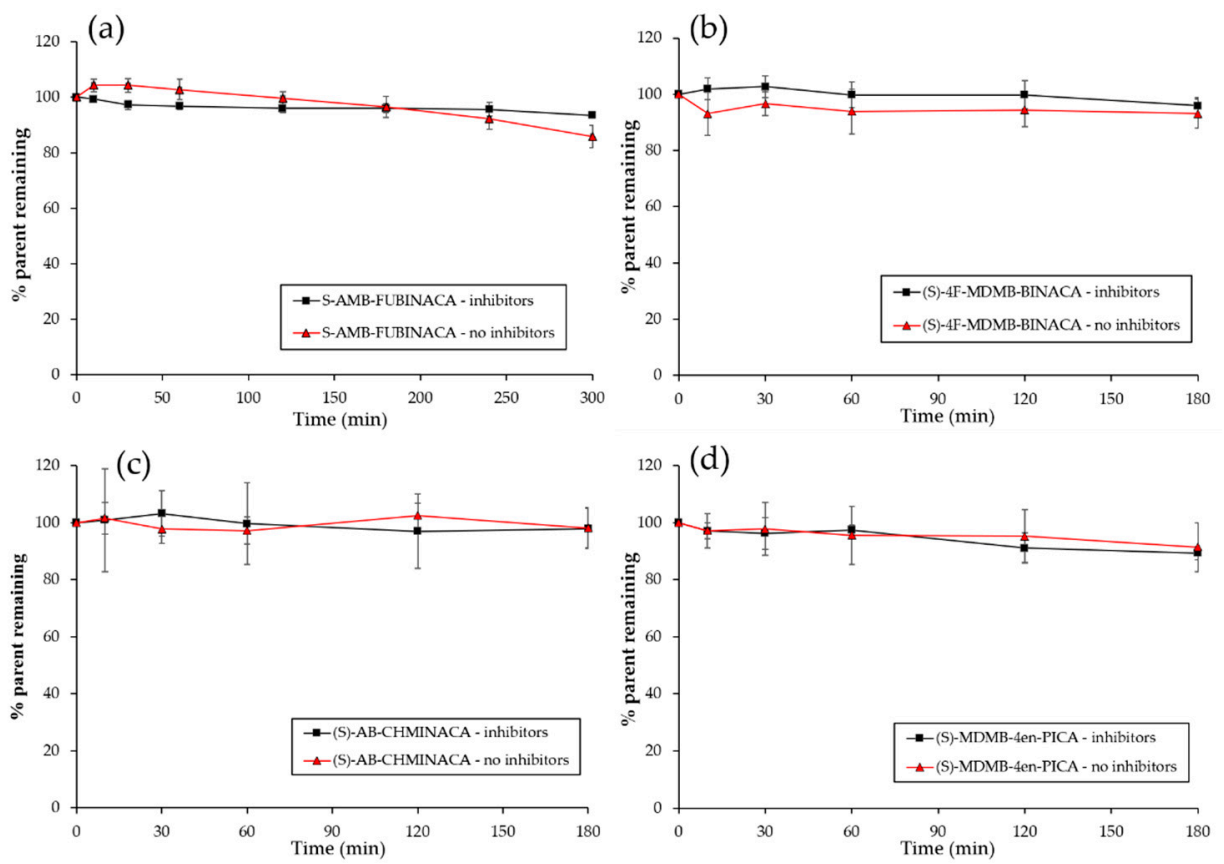

Figure 2. Stability of SCRAs (a) (S)-AMB-FUBINACA (1); (b) (S)-4F-MDMB-BINACA (4); (c) (S)AB-CHMINACA (11); (d) (S)-MDMB-4en-PICA (12) in pooled human plasma in the presence and absence of esterase enzyme $(n \geq 3 \pm \mathrm{SD})$. Full data in Section S5 of the supplementary information.

The instability of methyl ester containing SCRAs in plasma has previously been linked to the presence of CES-1 enzymes [76], however, whilst present in the liver and lung, CES-1 is not present in human plasma [66,67]. Human plasma contains other esterases such as butyrylcholinesterase (BchE), paraoxonase (PON-1), albumin esterase (a 'pseudo-esterase') and acetylcholinesterase (AchE) [66-68] and therefore it is these enzymes that may be involved in the degradation of SCRAs with methyl ester moieties, although non-enzymatic hydrolysis may also be involved [64].

\subsection{Plasma Protein Binding (PPB)}

The experimentally derived PPB values for the majority of SCRAs in this study are shown in Table 3 (some $(R$ )-enantiomers were not tested due to reference standard availability). All SCRAs were highly protein bound, with PPB ranging from 88.9-99.5\%. For the positive controls, warfarin and nicardipine, binding values were $98.4 \%$ and $97.7 \%$, respectively, in agreement with literature data $[77,78]$. The observed binding of the SCRAs reported in this study were in line with plasma protein binding data previously reported for THC [33] and is related to the lipophilicity of the SCRAs tested [13,79]. Thermal stability controls, which consisted of spiked plasma stored at $4{ }^{\circ} \mathrm{C}$ and $37^{\circ} \mathrm{C}$ for the duration of the experiment, showed that most compounds remained stable (total peak area in dialysed sample $>95 \%$ of the peak area in the non-dialysed sample). SCRAs for which recovery (total peak area in dialysed samples) was $\leq 95 \%$ that of $4{ }^{\circ} \mathrm{C}$ samples were all valine methyl ester (AMB-) compounds ((S)-AMB-FUBINACA (1) recovery $=77 \pm 4.4 \%, n=3$; $(R)$-AMB4en-PICA (7) recovery $=95 \pm 2.0 \%, n=3$ ). This agrees with available plasma stability data for the 3- and 5-h incubations reported here and with published long-term stability studies $[63,65]$. These findings all support the view that SCRAs containing a valine methyl ester head group are less stable in plasma than those containing a tert-leucine methyl ester or tert-leucinamide/valinamide head group. 
Table 3. Plasma protein binding (PPB) of tested SCRA enantiomers.

\begin{tabular}{|c|c|c|c|}
\hline Compound & PPB (\%) & Fraction Unbound (fu) & $n=$ \\
\hline (S)-MDMB-FUBINACA (6) & $99.5 \pm 0.08$ & $0.005 \pm 0.0008$ & 3 \\
\hline (S)-MDMB-4en-PINACA (5) & $99.0 \pm 0.01$ & $0.010 \pm 0.0001$ & 3 \\
\hline (R)-MDMB-4en-PINACA (5) & $98.1 \pm 0.71$ & $0.019 \pm 0.0071$ & 3 \\
\hline (S)-AMB-CHMICA (9) & $98.8 \pm 0.06$ & $0.012 \pm 0.0006$ & 3 \\
\hline (S)-AMB-FUBINACA (1) & $98.1 \pm 0.08$ & $0.019 \pm 0.0008$ & 3 \\
\hline (S)-AB-FUBINACA (8) & $97.9 \pm 0.44$ & $0.021 \pm 0.0044$ & 3 \\
\hline (S)-5F-MDMB-PINACA (2) & $97.8 \pm 0.19$ & $0.022 \pm 0.0019$ & 3 \\
\hline (R)-5F-MDMB-PINACA (2) & $96.0 \pm 0.58$ & $0.040 \pm 0.0058$ & 4 \\
\hline$(S)$-AB-CHMINACA (11) & $97.2 \pm 2.19$ & $0.028 \pm 0.0219$ & 3 \\
\hline (S)-MDMB-4en-PICA (12) & $96.5 \pm 0.32$ & $0.035 \pm 0.0031$ & 4 \\
\hline (R)-MDMB-4en-PICA (12) & $94.7 \pm 1.11$ & $0.053 \pm 0.0111$ & 4 \\
\hline (S)-AMB-4en-PICA (7) & $94.7 \pm 0.37$ & $0.053 \pm 0.0037$ & 3 \\
\hline (R)-AMB-4en-PICA (7) & $94.1 \pm 0.10$ & $0.059 \pm 0.0010$ & 3 \\
\hline (S)-5F-AMB-PINACA (10) & $94.2 \pm 0.08$ & $0.058 \pm 0.0008$ & 3 \\
\hline (S)-4F-MDMB-BINACA (4) & $93.9 \pm 0.28$ & $0.061 \pm 0.0028$ & 3 \\
\hline (R)-4F-MDMB-BINACA (4) & $88.9 \pm 0.49$ & $0.111 \pm 0.0049$ & 4 \\
\hline (S)-5F-MDMB-PICA (3) & $93.8 \pm 0.07$ & $0.062 \pm 0.0007$ & 3 \\
\hline (R)-5F-MDMB-PICA (3) & $93.8 \pm 0.15$ & $0.062 \pm 0.0015$ & 3 \\
\hline
\end{tabular}

As the equilibrium dialysis method employed to determine PPB involves the measurement of the ratio of bound to unbound analyte at the end of the equilibration period, the instability observed for the valine methyl ester SCRAs will not affect the calculated binding value [80].

\subsection{In Vitro Intrinsic Clearance}

The in vitro metabolic stability of the tested $(S)$ - and $(R)$-SCRA enantiomers in pHLM and pHHeps incubations are summarised in Tables 4 and 5, respectively. Each batch of pHLM and pHHeps used in the study comprised pooled biological material from 50 donors, 25 male and 25 female, of varying ages and health status. Details of the donors to each batch are provided in the certificate of analysis associated with each batch (see Section 3.1 for further details of donors). It is recognized that there will be interand intra-individual variation in SCRA metabolism, due to age, sex, health status and polymorphisms [81]. The use of large donor pools for pHLM and pHHeps batches $(n=50)$ reduces inter-batch variation and provides information on the fundamental structure metabolism relationships of SCRA analogues within and between structural classes, and intrinsic clearance rates obtained relate to the enzyme expression of an 'average individual'. This study does not set out to study differences in the ability of individuals, or phenotypes to metabolise SCRAs. Positive controls included with all test batches showed acceptable clearance; verapamil $\mathrm{CL}_{\text {int }}$ in pHLM ranged from $153-360 \mathrm{~mL} \mathrm{~min}^{-1} \mathrm{~kg}^{-1}$, while $\mathrm{CL}_{\text {int }}$ in cryopreserved pHHeps ranged from $117-179 \mathrm{~mL} \mathrm{~min}^{-1} \mathrm{~kg}^{-1}$, within the expected ranges for our laboratory and in line with literature reports [82-86]. Further positive controls for pHHep incubations, 7-ethoxycoumarin and 7-hydroxycoumarin, provided intrinsic clearance rates ranging from $55-305 \mathrm{~mL} \mathrm{~min}^{-1} \mathrm{~kg}^{-1}$ and $46-238 \mathrm{~min}^{-1} \mathrm{~kg}^{-1}$, respectively. The ranges observed cover normal batch variation for the metabolism of these compounds. Hepatocyte viability ranged from $90-94 \%$. All compounds were initially tested using a single pHHeps lot (HUE50-N, see Section 3.1 for further information on pool donors), allowing determination of fundamental differences in metabolic stability between compounds. A subset of compounds was further tested at a later date using pHHeps lot HUE50-P. This gave an indication of potential between-batch variation, evident only for (R)-5F-MDMB-PINACA (2). Intrinsic clearance and predicted in vivo data calculated using alternative microsomal scaling factors and an alternative hepatocyte cell density reported in the literature are provided for microsome and hepatocyte incubations in Sections S6 and S7 of the supplementary information, respectively. 
Table 4. In vitro half-life, microsomal clearance $\left(\mathrm{CL}_{\text {int micr }}\right)$ and intrinsic clearance $\left(\mathrm{CL}_{\mathrm{int}}\right)$ with predicted in vivo hepatic clearance $\left(\mathrm{CL}_{\mathrm{H}}\right)$ and hepatic extraction ratio $\left(\mathrm{E}_{\mathrm{H}}\right)$ for pooled human liver microsome incubations $(n \geq 3 \pm \mathrm{SD})$. As plasma protein values are not available for some SCRA $(R)$-enantiomers, hepatic clearance and hepatic extraction ratio values have not been calculated.

\begin{tabular}{|c|c|c|c|c|c|c|}
\hline Compound & $\begin{array}{c}T_{1 / 2} \\
\text { (min) }\end{array}$ & $\begin{array}{l}\text { Microsomal Intrinsic } \\
\text { Clearance, } \mathrm{CL}_{\text {int micr }} \\
\quad\left(\mathrm{mL} \text { min }^{-1} \mathrm{mg}\right. \\
\text { Microsomal Protein }\end{array}$ & $\begin{array}{c}\text { Intrinsic } \\
\text { Clearance, } C^{-} L_{\text {int }} \\
\left(\mathrm{mL} \mathrm{min}^{-1}\right. \\
\left.\text { kg }^{-1}\right)\end{array}$ & $\begin{array}{c}\text { Predicted In } \\
\text { Vivo Hepatic } \\
\text { Clearance, } \\
\text { CL }(\mathrm{mL} \\
\left.\min ^{-1} \mathrm{~kg}^{-1}\right)\end{array}$ & $\begin{array}{l}\text { Hepatic } \\
\text { Extraction } \\
\text { Ratio, } \mathrm{E}_{\mathrm{H}}\end{array}$ & $n$ \\
\hline (S)-AMB-FUBINACA (1) & $0.6 \pm 0.02$ & $2.182 \pm 0.071$ & $2944 \pm 95.9$ & $15.27 \pm 0.14$ & $0.73 \pm 0.006$ & 3 \\
\hline$(R)$-AMB-FUBINACA (1) & $5.9 \pm 0.48$ & $0.237 \pm 0.020$ & $320 \pm 26.8$ & - & - & 6 \\
\hline (S)-5F-AMB-PINACA (10) & $0.9 \pm 0.07$ & $1.494 \pm 0.115$ & $2016 \pm 155.7$ & $17.79 \pm 0.20$ & $0.85 \pm 0.010$ & 6 \\
\hline (R)-5F-AMB-PINACA (10) & $6.5 \pm 0.42$ & $0.213 \pm 0.014$ & $288 \pm 19.1$ & - & - & 6 \\
\hline (S)-AMB-CHMICA (9) & $4.1 \pm 0.75$ & $0.343 \pm 0.069$ & $463 \pm 92.9$ & $4.37 \pm 0.68$ & $0.21 \pm 0.032$ & 3 \\
\hline (R)-AMB-CHMICA (9) & $8.4 \pm 1.0$ & $0.167 \pm 0.019$ & $226 \pm 25.4$ & - & - & 3 \\
\hline (S)-AMB-4en-PICA (7) & $6.0 \pm 1.0$ & $0.236 \pm 0.042$ & $318 \pm 56.6$ & $9.29 \pm 0.89$ & $0.44 \pm 0.042$ & 10 \\
\hline (R)-AMB-4en-PICA (7) & $4.1 \pm 0.75$ & $0.348 \pm 0.068$ & $469 \pm 92.2$ & $11.8 \pm 0.97$ & $0.56 \pm 0.046$ & 11 \\
\hline (S)-MDMB-4en-PINACA (5) & $6.3 \pm 1.0$ & $0.226 \pm 0.037$ & $305 \pm 49.3$ & $2.66 \pm 0.37$ & $0.13 \pm 0.018$ & 7 \\
\hline (R)-MDMB-4en-PINACA (5) & $5.5 \pm 0.59$ & $0.253 \pm 0.026$ & $341 \pm 34.6$ & $4.94 \pm 0.39$ & $0.24 \pm 0.019$ & 7 \\
\hline (S)-5F-MDMB-PINACA (2) & $6.7 \pm 0.31$ & $0.207 \pm 0.009$ & $280 \pm 12.8$ & $4.76 \pm 0.17$ & $0.23 \pm 0.008$ & 5 \\
\hline (R)-5F-MDMB-PINACA (2) & $8.0 \pm 1.1$ & $0.176 \pm 0.024$ & $237 \pm 31.7$ & $6.52 \pm 0.61$ & $0.31 \pm 0.029$ & 5 \\
\hline (S)-5F-MDMB-PICA (3) & $9.0 \pm 1.4$ & $0.156 \pm 0.027$ & $211 \pm 36.9$ & $8.01 \pm 0.84$ & $0.38 \pm 0.04$ & 3 \\
\hline (R)-5F-MDMB-PICA (3) & $11 \pm 0.11$ & $0.132 \pm 0.001$ & $178 \pm 1.86$ & $7.22 \pm 0.05$ & $0.34 \pm 0.002$ & 3 \\
\hline (S)-MDMB-4en-PICA (12) & $8.5 \pm 1.3$ & $0.166 \pm 0.024$ & $224 \pm 32.4$ & $5.69 \pm 0.61$ & $0.27 \pm 0.029$ & 11 \\
\hline (R)-MDMB-4en-PICA (12) & $5.4 \pm 0.74$ & $0.260 \pm 0.040$ & $350 \pm 53.3$ & $9.81 \pm 0.75$ & $0.47 \pm 0.036$ & 9 \\
\hline (S)-4F-MDMB-BINACA (4) & $9.9 \pm 1.9$ & $0.143 \pm 0.025$ & $193 \pm 33.8$ & $7.51 \pm 0.88$ & $0.36 \pm 0.042$ & 3 \\
\hline (R)-4F-MDMB-BINACA (4) & $14 \pm 0.68$ & $0.096 \pm 0.005$ & $130 \pm 6.26$ & $8.55 \pm 0.24$ & $0.41 \pm 0.012$ & 3 \\
\hline (S)-MDMB-FUBINACA (6) & $11 \pm 2.4$ & $0.135 \pm 0.030$ & $183 \pm 40.2$ & $0.87 \pm 0.18$ & $0.04 \pm 0.009$ & 6 \\
\hline (R)-MDMB-FUBINACA (6) & $20 \pm 2.5$ & $0.071 \pm 0.009$ & $95.4 \pm 12.3$ & - & - & 6 \\
\hline (S)-AB-CHMINACA (11) & $27 \pm 2.9$ & $0.051 \pm 0.005$ & $69.1 \pm 7.35$ & $1.77 \pm 0.17$ & $0.08 \pm 0.008$ & 3 \\
\hline (R)-AB-CHMINACA (11) & $43 \pm 5.0$ & $0.033 \pm 0.004$ & $44.1 \pm 4.89$ & - & - & 3 \\
\hline (S)-AB-FUBINACA (8) & $118 \pm 28$ & $0.012 \pm 0.003$ & $16.4 \pm 4.24$ & $0.34 \pm 0.09$ & $0.02 \pm 0.004$ & 3 \\
\hline (R)-AB-FUBINACA (8) & $145 \pm 45$ & $0.010 \pm 0.003$ & $13.7 \pm 4.06$ & - & - & 3 \\
\hline
\end{tabular}

Table 5. In vitro half-life and intrinsic clearance $\left(\mathrm{CL}_{\mathrm{int}}\right)$ with predicted in vivo hepatic clearance $\left(\mathrm{CL}_{\mathrm{H}}\right)$ and hepatic extraction ratio $\left(E_{\mathrm{H}}\right)$ for pooled human cryopreserved hepatocyte incubations $(n \geq 3 \pm \mathrm{SD})$. As plasma protein values are not available for some SCRA $(R)$-enantiomers, hepatic clearance and hepatic extraction ratio values have not been calculated.

\begin{tabular}{|c|c|c|c|c|c|}
\hline Compound & $\begin{array}{c}T_{1 / 2} \\
(\min )\end{array}$ & $\begin{array}{c}\text { Intrinsic } \\
\text { Clearance, } C_{\text {int }} \\
\left(\mathrm{mL} \min ^{-1} \mathrm{~kg}^{-1}\right)\end{array}$ & $\begin{array}{l}\text { Predicted In Vivo Hepatic } \\
\text { Clearance, } \mathrm{CL}_{\mathrm{H}}\left(\mathrm{mL} \mathrm{min}^{-1}\right. \\
\left.\mathrm{kg}^{-1}\right)\end{array}$ & $\begin{array}{c}\text { Hepatic Extraction } \\
\text { Ratio, } \mathrm{E}_{\mathrm{H}}\end{array}$ & $n$ \\
\hline (S)-AMB-FUBINACA (1) & $2.5 \pm 0.55$ & $3216 \pm 607$ & $15.52 \pm 0.85$ & $0.74 \pm 0.041$ & 8 \\
\hline (R)-AMB-FUBINACA (1) & $3.1 \pm 0.57$ & $2557 \pm 463$ & - & - & 8 \\
\hline (S)-5F-AMB-PINACA (10) & $3.2 \pm 0.16$ & $2404 \pm 125$ & $18.25 \pm 0.12$ & $0.87 \pm 0.006$ & 3 \\
\hline (R)-5F-AMB-PINACA (10) & $4.7 \pm 0.26$ & $1623 \pm 87.0$ & - & - & 3 \\
\hline (S)-AMB-4en-PICA (7) & $6.9 \pm 2.1$ & $1205 \pm 363$ & $15.56 \pm 1.24$ & $0.74 \pm 0.059$ & 8 \\
\hline (R)-AMB-4en-PICA (7) & $5.5 \pm 2.1$ & $1589 \pm 616$ & $16.79 \pm 1.33$ & $0.80 \pm 0.063$ & 8 \\
\hline (S)-AMB-CHMICA (9) & $7.6 \pm 0.35$ & $1011 \pm 48.5$ & $7.68 \pm 0.22$ & $0.37 \pm 0.011$ & 3 \\
\hline (R)-AMB-CHMICA (9) & $8.3 \pm 0.35$ & $918 \pm 38.2$ & - & - & 3 \\
\hline (S)-MDMB-4en-PINACA (5) & $12 \pm 2.6$ & $683 \pm 158$ & $5.11 \pm 0.89$ & $0.24 \pm 0.042$ & 7 \\
\hline (R)-MDMB-4en-PINACA (5) & $22 \pm 3.6$ & $363 \pm 66.5$ & $5.16 \pm 0.70$ & $0.25 \pm 0.033$ & 7 \\
\hline
\end{tabular}


Table 5. Cont.

\begin{tabular}{|c|c|c|c|c|c|}
\hline Compound & $\begin{array}{c}\mathrm{T}_{1 / 2} \\
\text { (min) }\end{array}$ & $\begin{array}{c}\text { Intrinsic } \\
\text { Clearance, } \mathrm{CL}_{\mathrm{int}} \\
\left(\mathrm{mL} \min ^{-1} \mathrm{~kg}^{-1}\right)\end{array}$ & $\begin{array}{l}\text { Predicted In Vivo Hepatic } \\
\text { Clearance, } \mathrm{CL}_{\mathrm{H}}\left(\mathrm{mL} \mathrm{min} \mathrm{min}^{-1}\right. \\
\left.\mathrm{kg}^{-1}\right)\end{array}$ & $\begin{array}{c}\text { Hepatic Extraction } \\
\text { Ratio, } \mathrm{E}_{\mathrm{H}}\end{array}$ & $n$ \\
\hline (S)-5F-MDMB-PINACA (2) & $13 \pm 3.3$ & $604 \pm 135$ & $8.05 \pm 1.15$ & $0.38 \pm 0.055$ & 12 \\
\hline (R)-5F-MDMB-PINACA (2) & $23 \pm 1.8$ & $334 \pm 25.5$ & $8.16 \pm 0.38$ & $0.39 \pm 0.018$ & 6 \\
\hline (S)-4F-MDMB-BINACA (4) & $16 \pm 0.74$ & $466 \pm 21.6$ & $12.08 \pm 0.23$ & $0.58 \pm 0.011$ & 3 \\
\hline (R)-4F-MDMB-BINACA (4) & $58 \pm 17.2$ & $139 \pm 37.4$ & $8.77 \pm 1.43$ & $0.42 \pm 0.068$ & 4 \\
\hline (S)-MDMB-FUBINACA (6) & $26 \pm 5.0$ & $298 \pm 62.7$ & $1.39 \pm 0.27$ & $0.07 \pm 0.013$ & 3 \\
\hline (R)-MDMB-FUBINACA (6) & $32 \pm 5.4$ & $239 \pm 40.7$ & - & - & 3 \\
\hline (S)-MDMB-4en-PICA (12) & $37 \pm 6.9$ & $213 \pm 41.6$ & $5.46 \pm 0.78$ & $0.26 \pm 0.037$ & 7 \\
\hline (R)-MDMB-4en-PICA (12) & $44 \pm 6.3$ & $176 \pm 24.0$ & $6.42 \pm 0.62$ & $0.31 \pm 0.029$ & 7 \\
\hline (S)-5F-MDMB-PICA (3) & $38 \pm 4.6$ & $204 \pm 23.2$ & $7.87 \pm 0.58$ & $0.37 \pm 0.027$ & 3 \\
\hline (R)-5F-MDMB-PICA (3) & $54 \pm 9.4$ & $145 \pm 24.1$ & $6.27 \pm 0.74$ & $0.30 \pm 0.035$ & 3 \\
\hline (S)-AB-CHMINACA (11) & $39 \pm 8.8$ & $210 \pm 72.9$ & $4.52 \pm 1.12$ & $0.22 \pm 0.053$ & 6 \\
\hline (R)-AB-CHMINACA (11) & $38 \pm 8.7$ & $213 \pm 54.3$ & - & - & 5 \\
\hline (S)-AB-FUBINACA (8) & $76 \pm 24$ & $110 \pm 34.5$ & $2.06 \pm 0.58$ & $0.10 \pm 0.028$ & 8 \\
\hline (R)-AB-FUBINACA (8) & $69 \pm 11$ & $113 \pm 15.6$ & - & - & 8 \\
\hline
\end{tabular}

\subsubsection{Comparison of SCRA (S)-Enantiomer Intrinsic Clearance Rates and Half-Lives}

The (S)-enantiomers of valinate and tert-leucinate indazole- and indole-3-carboxamide SCRAs are known to be much more prevalent and more potent than the $(R)$-enantiomers and are often more efficacious [1,31]. For the (S)-enantiomers tested in this study, the order of the in vitro intrinsic clearance rate was $\mathrm{AMB}>\mathrm{MDMB}>\mathrm{AB}$-compounds in both pHLM and pHHeps (Tables 4 and 5; Figures 3 and 4). Data showing the clearance of each enantiomer pair are provided in Sections S6 and S7 of the supplementary information for pHLM and pHHeps, respectively). The in vitro half-lives of SCRAs in pHLM incubations ranged from $118 \pm 28 \mathrm{~min}$ for (S)-AB-FUBINACA (8) to $0.60 \pm 0.02 \mathrm{~min}$ for (S)-AMB-FUBINACA (1). In pHHeps, half-lives ranged from $76 \pm 24 \mathrm{~min}$ for (S)-ABFUBINACA (8) and $2.50 \pm 0.55 \mathrm{~min}$ for (S)-AMB-FUBINACA (1). In vitro pHLM intrinsic clearance for some compounds (e.g., (S)-AMB-FUBINACA (1) and (S)-5F-AMB-PINACA (10) (methyl [1-(5-fluoropentyl)- $1 \mathrm{H}$-indazole-3-carbonyl]valinate)) was so fast that it was challenging to accurately calculate intrinsic clearance rates and half-lives (see Figures S22 and S32 in Section S6 of the supplementary information). The presence of a valinamide head group (AB-compounds) increased drug half-life, slowing clearance compared to SCRAs with a more labile methyl ester moiety (AMB- and MDMB-compounds). However, AB-CHMINACA (11) (N-[1-amino-3-methyl-1-oxobutan-2-yl]-1-(cyclohexylmethyl)-1Hindazole-3-carboxamide) clearance in hepatocytes was comparable to that of the slowest cleared tert-leucine methyl ester (MDMB-) compounds, possibly due to the relative lability of the cyclohexyl tail group to enzymatic attack [87]. tert-Leucine methyl ester (MDMBcompounds), having a trimethyl moiety in the head group, are metabolised at a slower rate than those with a dimethyl moiety in the head group (AMB-, valine methyl ester compounds). This could be due to steric hindrance caused by the extra methyl group adjacent to the methyl ester, one of the principal sites of biotransformation.

The differences in clearance rates between SCRA compounds which differ only by their head group (AB-, AMB- and MDMB-compounds) and which had either a fluorobenzyl tail group (FUBINACAs) or a fluoropentyl tail group (PINACAs) is illustrated in Figure 4.

Although no tert-leucinamide SCRAs (ADB-type SCRAs) were investigated in this study, it might logically be concluded that their intrinsic clearance is likely to be similar or even slower than the valinamide SCRAs (AB-type SCRAs), however this requires further experimental confirmation. The in vitro clearance of SCRAs with indazole cores ("INACA" compounds) is faster in both pHLM and pHHeps than their equivalent indole 
analogues ("ICA" compounds), e.g., 5F-MDMB-PINACA (2) vs. 5F-MDMB-PICA (3) and MDMB-4en-PINACA (5) vs. MDMB-4en-PICA (12) (methyl 3,3-dimethyl-2-[1-(pent-4-en-1yl)-1H-indole-3-carboxamido]butanoate) (Tables 4 and 5).

Overall, these findings corroborate data from a number of previous studies: Franz et al. (2019) [37] demonstrated that indoles were significantly less metabolically reactive than their indazole analogues during in vitro pHLM studies; Hess et al. (2017) [65] demonstrated that long term stability in non-frozen plasma $\left(4^{\circ} \mathrm{C}\right.$ and $\left.20^{\circ} \mathrm{C}\right)$ was of the order AB-FUBINACA = ADB-FUBINACA ( $N$-(1-amino-3,3-dimethyl-1-oxobutan-2-yl)-1(4-fluorobenzyl)-1H-indole-3-carboxamide) > MDMB-FUBINACA > AMB-FUBINACA; Krotulski et al. (2020) [63] showed that the order of stability in non-frozen whole blood was ADB-FUBINACA > 5F-MDMB-PICA > 5F-MDMB-PINACA > AMB-FUBINACA.
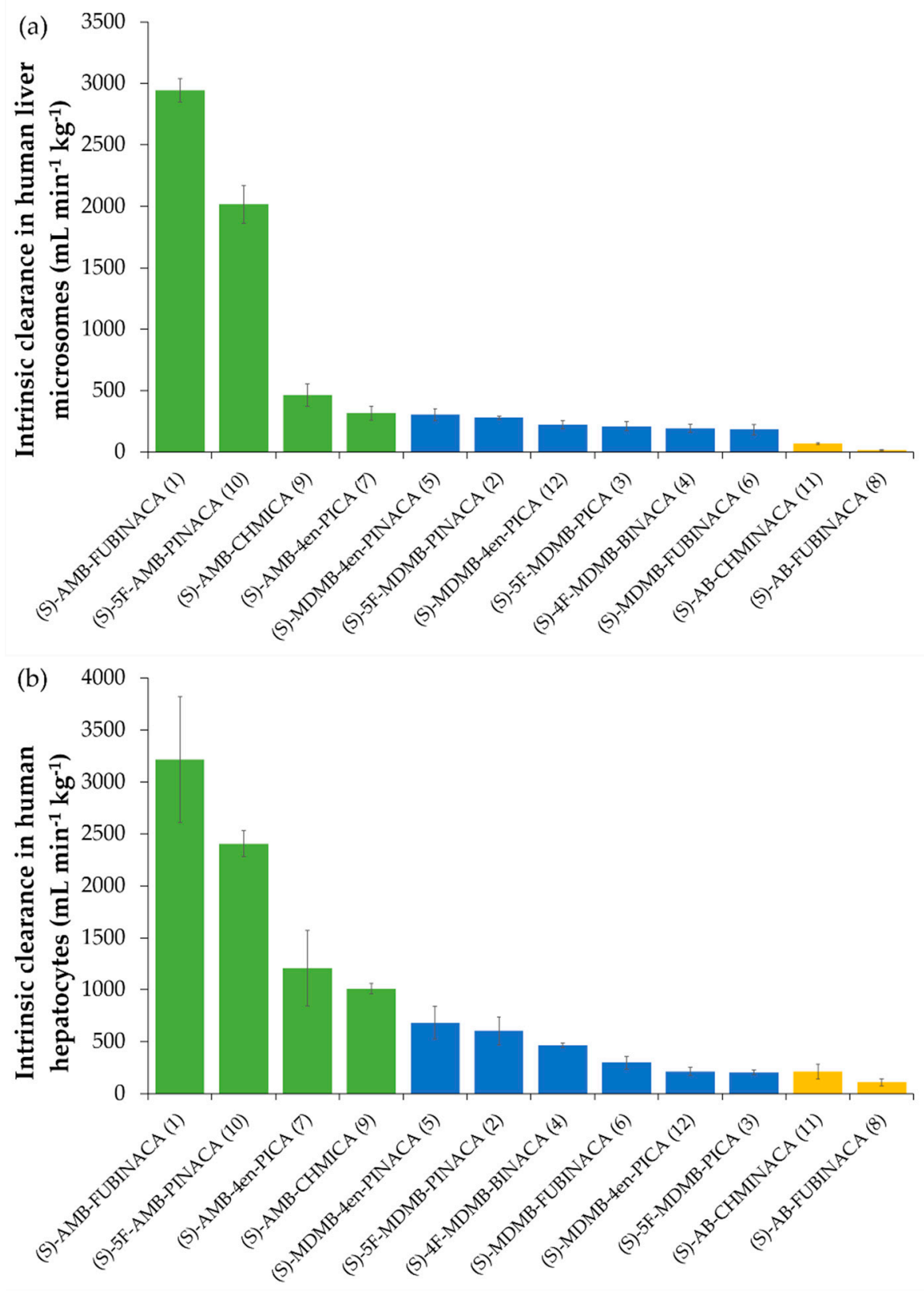

Figure 3. Intrinsic clearance ( $\left.\mathrm{CL}_{\text {int }}, \mathrm{mL} \mathrm{min}^{-1} \mathrm{~kg}^{-1}\right)$ of SCRAs ((S)-enantiomers) in (a) pooled human liver microsome incubations $(n \geq 3 \pm \mathrm{SD})$; (b) pooled cryopreserved human hepatocyte incubations $(n \geq 3 \pm \mathrm{SD})$. 


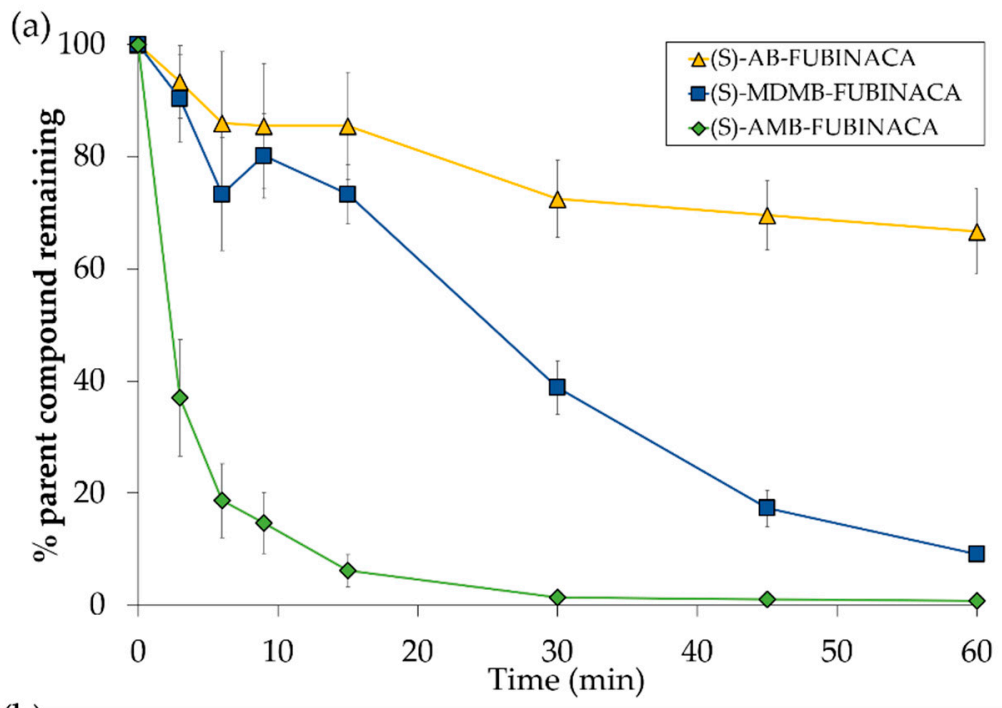

(b)

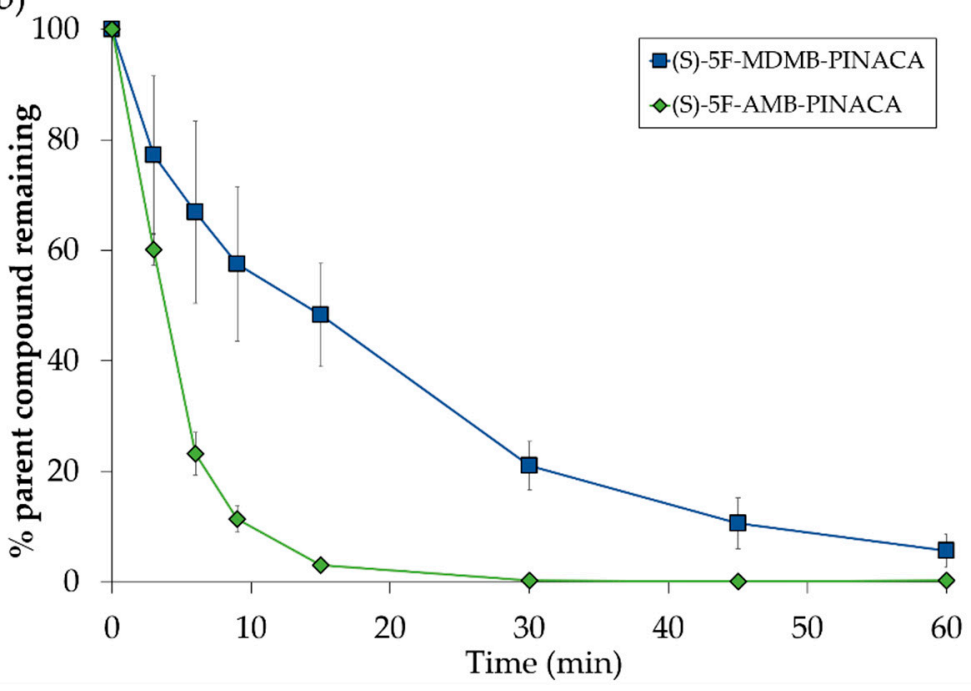

Figure 4. (a) Differences in clearance of (S)-AB-FUBINACA (8), (S)-MDMB-FUBINACA (6) and (S)AMB-FUBINACA (1) incubated in pooled human cryopreserved hepatocytes (pHHeps) $(n \geq 3 \pm$ SD). (b) Differences in clearance of (S)-5F-MDMB-PINACA (2) and (S)-5F-AMB-PINACA (10) incubated in pooled human cryopreserved hepatocytes (pHHeps) $(n \geq 3 \pm \mathrm{SD})$.

The reactivity/lability of the methyl ester and amide moieties within the valinate and tert-leucinate indole and indazole-3-carboxamide SCRAs appears to be the determining step for their in vitro clearance rates, the type of metabolites formed in vitro and in vivo and their stability ex vivo in whole blood and plasma. It is therefore logical that in both this study and in other studies, AMB-FUBINACA (1) has been found to be among the most metabolically unstable compounds studied. The reasons being that the methyl ester moiety is fundamentally unstable; there is little steric hindrance to slow down enzymatic hydrolysis of the methyl ester by esterases; the molecule is relatively more reactive due to its indazole core compared to indole compounds, and other sites of metabolism on the molecule are limited due to the presence of the stable fluorobenzyl moiety.

\subsubsection{The Influence of Chirality on Intrinsic Clearance Rates and Half-Lives}

As enantioselectivity is common in both metabolism and pharmacology [88], comparison of the intrinsic clearance and half-lives between enantiomer pairs can provide some further fundamental information on the influence of structural and conformational features on the molecular interactions between SCRA substrates and metabolic enzymes. 
There were some notable differences in the half-lives and intrinsic clearance derived from the incubation of $(R)$ - and $(S)$ - enantiomers with pHLM (Table 4, Section S6 of the supplementary information). For most compounds, the (S)-enantiomer was consistently cleared at a faster rate than the $(R)$-enantiomer, particularly for AMB-FUBINACA (1) and 5F-AMB-PINACA (10).

For those compounds with an alkene tail (4en compounds), there was either no difference between enantiomers (MDMB-4en-PINACA (5)) or the $(R)$-enantiomer was cleared faster (AMB-4en-PICA (7) and MDMB-4en-PICA (12)). When SCRA enantiomer pairs were incubated in pHHeps (Table 5, Section S7 of the supplementary information), there was negligible difference between the derived half-lives and intrinsic clearance rates of $(S)$ - and $(R)$-enantiomers for AB-compounds. For AMB-compounds there was a marginal difference between the intrinsic clearance and half-lives of the enantiomer pairs with $(S)$ enantiomers cleared at a faster rate. tert-Leucine methyl ester SCRAs without an alkene tail group (5F-MDMB-PINACA (2), 5F-MDMB-PICA (3), 4F-MDMB-BINACA (4) and MDMBFUBINACA (6)), showed the greatest difference in intrinsic clearance rates between the $(S)$ - and $(R)$-enantiomers, with the $(S)$-enantiomers consistently cleared at a faster rate. Of the tert-leucine methyl ester SCRAs with an alkene tail group (-4en-compounds), the $(S)$-enantiomer of MDMB-4en-PINACA (5) was cleared faster than the $(R)$-enantiomer but the intrinsic clearance of the enantiomer pairs of AMB-4en-PICA (7) and MDMB-4en-PICA (12) was similar.

In this study, the majority of pHHep incubations were carried out using hepatocytes of a single lot number, however 5F-MDMB-PINACA (2) was tested using two different lots of pHHep cells. In initial pHHep incubations (lot HUE50-N), incubation of (S)-5FMDMB-PINACA and (R)-5F-MDMB-PINACA (2) gave half-lives of $13.3 \pm 3.4 \mathrm{~min}(n=8)$ and $22.9 \pm 1.8 \mathrm{~min}(n=6)$ respectively, while in pHHep lot HUE50-P, half-lives were $13.2 \pm 3.4 \mathrm{~min}(n=4)$ and $6.5 \pm 0.13 \mathrm{~min}(n=4)$, respectively. The increased clearance of $(R)$-5F-MDMB-PINACA (2) in the latter incubation suggests a difference in expression of enzyme(s) in this lot of cells, but no such differences were observed for the other compounds tested (MDMB-4en-PINACA (5), MDMB-4en-PICA (12) and AMB-4en-PICA (7)) using the two different pHHep lots.

\subsubsection{Comparison of Intrinsic Clearance Calculated from $\mathrm{pHLM}$ and $\mathrm{pHHeps}$}

For all compounds, with the exceptions of $(R)-5$ F-MDMB-PICA (3) and $(R)$-MDMB4en-PICA (12), intrinsic clearance scaled to whole-liver dimensions for pHHeps was faster than or comparable to that of pHLM. For all MDMB- compounds, and for most $(S)$ AMB-compounds differences in $\mathrm{CL}_{\text {int }}$ were within 2.5-fold. Those containing an amide (AB-compounds) rather than a methyl ester group, and thus forming an amide hydrolysis product as a major metabolite $[69,87]$, showed the greatest differences in intrinsic clearance between pHLM and pHHeps but were cleared the slowest overall. There are multiple factors which can cause intrinsic clearance by HHeps to differ from HLM [89]. Differences may reflect the relative efficiency of transport of SCRAs and their enantiomers through cell membranes in HHeps and the relative abundance of particular enzymes in HLM and HHeps, targeting different sites of metabolism, particularly carboxylesterases. A dominance of non-CYP enzymes in metabolic clearance can result in $\mathrm{CL}_{\text {int }}$ being faster in HHeps. The degree of Phase II glucuronidation thought to be produced from these drugs varies, but glucuronidation here only occurs after some form of Phase I biotransformation and is generally minimal compared to other pathways [56,64,69-71,90]; these studies however did not utilise metabolite reference standards or beta-oxidation for confirmation. Glucuronidation is therefore unlikely to cause the differences in clearance rates observed. Carboxylesterase enzymes are non-CYP enzymes, but are present in microsomes and do not require cofactor [91]. CES-1 is one of the most abundant enzymes in human hepatocytes, present in the endoplasmic reticulum and to a lesser extent in the cytosol $[67,88,91]$. Non-specific binding of drugs to microsomes and hepatocytes results in a lower unbound fraction available to interact with enzymes; differences in binding between HLM and HHep incubations 
may therefore also cause clearance differences [89]. Non-specific binding may be estimated from $\log P$ data $[92,93]$. Theoretical fraction unbound for microsomes $\left(\mathrm{fu}_{\mathrm{mic}}\right)$ and hepatocytes $\left(\mathrm{fu}_{\mathrm{hep}}\right)$ was calculated using experimental pHLM and pHHep concentrations and incubation volumes, and experimental $\log \mathrm{D}_{7.4}$ values, as described by Kilford et al. (2008) [92] with hepatocyte cell volume as $3.9 \mu \mathrm{L} /$ million cells [94]. In this study, fu $\mathrm{fu}_{\text {mic }}$ ranged from 0.18-0.82 $(n=12$, median $=0.42)$, while fu $\mathrm{u}_{\text {hep }}$ ranged from $0.47-0.95(n=12$, median $=0.75$ ). These results suggest in vivo hepatocyte binding is mostly limited (except, perhaps for MDMB-4en-PINACA (5) (estimated fu hep 0.47)), while microsomal binding is greater. However, differences in predicted binding did not necessarily correlate with differences in clearance, so this is unlikely to be a significant factor.

\subsection{Prediction of Human In Vivo Clearance}

When PPB was considered in the prediction of in vivo hepatic clearance (see Table 3), clearance rates were, as would be expected, much slower than in vitro values (Tables 4 and 5). Hepatic clearance predicted from pHLM incubations ranged from $0.34 \mathrm{~mL} \mathrm{~min}{ }^{-1} \mathrm{~kg}^{-1}$ ((S)-AB-FUBINACA (8)) to $17.79 \mathrm{~mL} \mathrm{~min}^{-1} \mathrm{~kg}^{-1}((S)-5 \mathrm{~F}-A M B-P I N A C A(10))$. Hepatic clearance predicted from $\mathrm{pHHep}$ incubations ranged from $1.39 \mathrm{~mL} \mathrm{~min}{ }^{-1} \mathrm{~kg}^{-1}((S)$-MDMBFUBINACA (6)) to $18.25 \mathrm{~mL} \mathrm{~min}^{-1} \mathrm{~kg}^{-1}$ ((S)-5F-AMB-PINACA (10)). Predicted in vivo hepatic clearance from HLM in vitro data were calculated to allow comparison with available literature values. They should be viewed cautiously for SCRAs with a terminal ester or amide moiety due to likely differences in CES-1 enzyme expression between pHLM and $\mathrm{pHHeps}$. However, in this study, no marked differences in predicted in vivo clearance rates between $\mathrm{pHLM}$ and pHHeps were observed. SCRA clearance studies have previously shown that true in vivo clearance is often slower than is predicted from in vitro data $[15,95]$. This is likely due to the lipophilicity and high degree of plasma protein binding of these compounds; for most SCRAs, PPB has not previously been characterised and so was not previously incorporated into the prediction of human in vivo rates. Hepatic clearance in this study has been predicted according to the 'well-stirred' model, where fu may be based on either blood or plasma binding data $[79,96]$. Here, plasma binding data were used and so it is assumed that the blood/plasma ratio of the test compounds is 1. Differences in binding in plasma versus whole blood could therefore influence the results. Hepatic extraction ratios (Tables 4 and 5) showed large differences between the compounds tested. The ratios ranged from 0.02 ((S)-AB-FUBINACA (8)) to 0.85 ((S)-5F-AMB-PINACA (10)) based on pHLM incubations, and from $0.07((S)$-MDMB-FUBINACA (6)) to $0.87((S)$-5FAMB-PINACA (10)) based on pHHep incubations. The fraction of drug predicted to be cleared with each pass of the liver therefore varies greatly between compounds. Although $(S)$-enantiomers tended to have faster intrinsic clearance rates in pHHeps, they also tended to be slightly more protein bound than $(R)$-enantiomers; thus, predicted in vivo clearance rates and hepatic extraction ratios were not substantially different between enantiomers.

For a small number of the SCRAs tested in this study, comparative intrinsic clearance data are available in the literature (Table 6), and data reported here was in overall agreement with the reported values. While studies of intrinsic clearance in $\mathrm{pHHeps}$ are limited, more studies have reported microsomal rates. Although not reported, it is assumed that the $(S)$-enantiomers have been tested in the literature studies. Castaneto et al. reported AB-FUBINACA (8) $\mathrm{CL}_{\text {int micr }}$ as $0.011 \mathrm{~mL} \mathrm{~min}^{-1} \mathrm{mg}^{-1}$, with intrinsic clearance of $10.5 \mathrm{~mL} \mathrm{~min}^{-1} \mathrm{~kg}^{-1}$ [69]. Presley et al. found 5F-MDMB-PINACA (2) $\mathrm{CL}_{\text {int micr }}$ to be $0.271 \mathrm{~mL} \mathrm{~min}^{-1} \mathrm{mg}^{-1}$, with an intrinsic clearance rate of $256.2 \mathrm{~mL} \mathrm{~min}^{-1} \mathrm{~kg}^{-1}$ [54]. These findings are in line with data reported here. However, as protein binding studies were unavailable at the time, $\mathrm{CL}_{\mathrm{H}}$ and $\mathrm{E}_{\mathrm{H}}$ predictions by Castaneto et al. and Presley et al. $[54,69]$ did not account for binding and so rates for this differ; based on pHLM incubations, $\mathrm{CL}_{\mathrm{H}}$ and $\mathrm{E}_{\mathrm{H}}$ predictions for AB-FUBINACA (8) [69] were 20-fold and 17-fold lower respectively when PPB was accounted for, while those for 5F-MDMB-PINACA (2) [54] were 4-fold lower in this study. Intrinsic clearance of 5F-AMB-PINACA (10) and AMB-4en-PICA (7) have also been reported previously, and both were similar to the data reported in this 
study [57,73]. Davidsen et al. (2010) [13] reported increasing metabolic stability of JWHtype SCRAs in HHeps with increasing size of halogen atom incorporated into the structure, with I-JWH-122 ((1-(5-iodopentyl)-1H-indol-3-yl)(4-methylnaphthalen-1-yl)methanone) being the most metabolically stable. The effect of incorporation of fluorine onto the pentyl tail group is unclear; for JWH-122 ((4-methyl-1-naphthyl)-(1-pentylindol-3-yl)methanone) (HHeps) and AMB-PINACA (methyl (1-pentyl-1H-indazole-3-carbonyl)valinate) (HLM), 5 -fluorination makes little difference to intrinsic clearance [13,73].

The 5-fluorination of Cumyl-PICA (1-pentyl- $\mathrm{N}$-(2-phenylpropan-2-yl)- $\mathrm{H}$-indole-3carboxamide) (HLM) results in faster clearance [95], while 5-fluorination of AB-PINACA (HLM) results in slower clearance [16]. As noted previously, the incorporation of fluorobenzene (e.g., FUB- or -FUBINACA compounds) tends to stabilise compounds, reducing clearance rates $[16,69,97]$.

In vivo hepatic clearance is related to both $\mathrm{CL}_{\mathrm{int}}$ and fu [79]; for many drugs, increasing $\log \mathrm{P}$ will increase $\mathrm{CL}_{\text {int }}$ but reduce fu. Thus, the effect of $\log \mathrm{P}$ on whole-body clearance can be unpredictable. However, increasing $\log \mathrm{P}$ can increase the volume of distribution of the unbound fraction [79]. Although the majority of the SCRAs studied here are rapidly metabolised in vitro, high levels of protein binding in vivo will extend the time they will circulate in the body following consumption. This potentially facilitates storage in lipid-rich tissues such as adipose tissue, particularly in chronic users. Detection windows of some compounds have been reported to be exceptionally long following drug cessation $[43,98,99]$. Franz et al. reported detection in urine of a metabolite common to AB-FUBINACA (8) and AMB-FUBINACA (1) two years after reported cessation of consumption, but did not determine which drug was responsible [43]. Hasegawa et al. (2015) reported detection of AB-CHMINACA (11) and 5F-AMB-PINACA (10) in a fatal poisoning case, where AB-CHMINACA (11) could be quantified in all solid tissues tested, while 5F-AMB-PINACA (10) could only be quantified in adipose tissue [98]. These data suggest extensive redistribution of synthetic cannabinoids in vivo. Experimental data presented here show hepatic clearance of AB-type SCRAs to be slower than that of MDMB- and AMBcompounds, with lower hepatic extraction ratios. However, the SCRAs are not metabolically stable enough to explain the recently reported long detection windows. Therefore, the presence of such compounds and their metabolites in body fluids after a considerable time is more likely to be evidence of tissue accumulation, subsequent leaching back into the circulatory system and metabolism of the unbound fraction. JWH- SCRAs have log P values which are similar to or greater than those of indole- and indazole-3-carboxamide SCRAs (and therefore likely similar or greater PPB), which may in part explain their extended detection windows in vivo [100,101], though specific structural features are likely also involved [39].

\subsection{Study Limitations}

A limitation to this study, and indeed other research studies related to the metabolism of constantly emerging SCRAs and other NPS using pHLM and pHHeps, is that it does not consider the expected variation in metabolic capacity between individual users. The aim of the study is, however, to provide comparative information for the metabolism of structurally related SCRAs in an 'average' human using pooled donor in vitro platforms, to allow the deconvolution of the key structural features of the SCRAs that affect metabolic stability in isolation. The study provides a more accurate estimate of in vivo human hepatic clearance than previously reported by taking into account the effect of plasma protein binding. This is the first time such information has been incorporated into in vivo hepatic clearance calculations for the SCRA structural classes studied. The study also does not consider other potential sites of metabolism likely to be important in SCRAs which are smoked or vaped, namely the lungs; no metabolic studies on SCRAs using lung microsomes have yet been reported in the literature. Metabolism by the lungs could occur to some degree as they contain numerous metabolising enzymes including, but not limited to, carboxylesterases such as CES-1 (but at a lower concentration than the 
liver) [102], likely to be the main enzyme responsible for methyl ester and amide hydrolysis of these SCRAs. The lungs also contain CYP450 enzymes as well as uridine 5'-diphosphoglucuronosyltransferase (UGT) enzymes (but with limited expression compared to other tissues) [103]. While Phase I metabolism in human lung parenchymal cells has shown less than $10 \%$ the activity of that of cryopreserved human hepatocytes, levels of ester hydrolysis, of great importance to the valinate- and tert-leucinate SCRAs included in this study, have been shown to be similar [104]. Through inhalation of SCRAs, the lungs will be exposed to high drug concentrations. It is unclear to what extent metabolism of valinate and tert-leucinate indole and indazole-3-carboxamide SCRAs in the lungs may affect the extent of SCRA biotransformation, and thus the bioavailability of the parent compound, before reaching systemic circulation.

Table 6. Literature values for intrinsic clearance $\left(\mathrm{CL}_{\mathrm{int}}\right)$ rates and half-lives $\left(\mathrm{t}_{1 / 2}\right)$ of SCRAs in human liver microsomes (HLM) and human hepatocytes (HHeps). Compounds marked with an asterisk $\left({ }^{*}\right)$ display pHHep data; all other data is from pHLM incubations.

\begin{tabular}{|c|c|c|c|c|}
\hline Compound & $\mathrm{CL}_{\text {int micr }}\left(\mathrm{mL} \mathrm{min}-1 \mathrm{mg}^{-1}\right)$ & 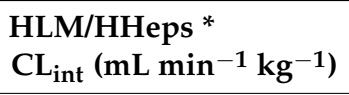 & $t_{1 / 2}(\min )$ & Reference \\
\hline JWH-122 * & - & 1350 & 0.95 & \multirow{5}{*}{ [13] } \\
\hline MAM-2201 * & - & 1408 & 0.88 & \\
\hline Cl-JWH-122 * & - & 502 & 2.46 & \\
\hline Br-JWH-122 * & - & 497 & 2.49 & \\
\hline I-JWH-122 * & - & 235 & 5.26 & \\
\hline AM1220* & - & 169 & 3.7 & [105] \\
\hline THJ-018 & 0.036 & 34.2 & 19.2 & \multirow{2}{*}[14]{} \\
\hline THJ-2201 & 0.064 & 60.8 & 10.8 & \\
\hline NNEI & 0.300 & 350 & 2.29 & \multirow{2}{*}{ [15] } \\
\hline MN-18 & 0.410 & 469 & 1.71 & \\
\hline NM-2201 & 0.088 & 81.6 & 8.0 & [106] \\
\hline BIM-2201 & 0.142 & 134.1 & 4.9 & [107] \\
\hline Cumyl-PICA & 0.12 & - & 5.92 & \multirow{2}{*}[95]{} \\
\hline 5F-Cumyl-PICA & 0.39 & - & 1.77 & \\
\hline STS-135 & 0.222 & 209 & 3.1 & [108] \\
\hline AMB-4en-PICA (7) & - & 291 & 2.1 & [57] \\
\hline AB-PINACA & 0.037 & 35 & 18.7 & \multirow{2}{*}[16]{} \\
\hline 5F-AB-PINACA & 0.019 & 18 & 35.9 & \\
\hline AMB-PINACA & & - & 1.1 & \multirow{2}{*}{ [73] } \\
\hline 5F-AMB-PINACA (10) & 0.67 & - & 1.0 & \\
\hline 5F-MDMB-PINACA (2) & 0.271 & 256.2 & 3.1 & [54] \\
\hline 5F-APP-PICA & 0.046 & - & 15.1 & \multirow{3}{*}{ [109] } \\
\hline 5F-APP-PINACA & 0.202 & - & 3.4 & \\
\hline APP-CHMINACA & 0.133 & - & 5.2 & \\
\hline AB-FUBINACA (8) & 0.011 & 10.5 & 62.6 & [69] \\
\hline ADB-FUBINACA & 0.018 & 16.5 & 39.7 & [17] \\
\hline FDU-PB-22 & 0.056 & 52.7 & 12.4 & \multirow{2}{*}{ [97] } \\
\hline FUB-PB-22 & 0.060 & 57.1 & 11.5 & \\
\hline
\end{tabular}

3. Materials and Methods

3.1. Chemicals and Reagents

The in-house enantiospecific synthesis of the $(R)$ - and $(S)$-enantiomers of AMBFUBINACA (1) (>98\% purity), 5F-MDMB-PINACA (5F-ADB) (2) (>99.6\% purity), 5FMDMB-PICA (3) (>99\% purity), 4F-MDMB-BINACA (4) (>99.7\% purity), MDMB-4enPINACA (5) (>98.6\% purity), MDMB-FUBINACA (6) (>99.9\% purity), AMB-4en-PICA (7) 
(>99.7\% purity), AB-FUBINACA (8) (>99\% purity), AMB-CHMICA (9) (MMB-CHMICA) (>99.6\% purity), 5F-AMB-PINACA (10) (5F-AMB) (>99.9\% purity), AB-CHMINACA (11) (>99\% purity) and MDMB-4en-PICA (12) (>99.7\% purity) has been described previously [1,31].

Donepezil, verapamil, 7-ethoxycoumarin (7-EC), bis(4-nitrophenyl) phosphate (BNPP), phenyl methyl sulphonyl fluoride (PMSF), procaine, warfarin, nicardipine, nicotinamide adenine dinucleotide phosphate (NADP), reduced NADP (NADPH), glucose-6-phosphate dehydrogenase (from baker's yeast S. cerevisiae), D-glucose-6-phosphate sodium salt, sodium bicarbonate, potassium phosphate buffers (monobasic and dibasic), formic acid (99\%) and dimethylsulfoxide (DMSO) were purchased from Sigma-Aldrich (Gillingham, UK). 7-hydroxycoumarin (7-HC) was purchased from Chem Service (West Chester, PA, USA). Analytical grade acetonitrile $(\mathrm{ACN})$ and methanol $(\mathrm{MeOH})$ were purchased from Sigma-Aldrich or Greyhound Chromatography (Birkenhead, UK).

Ultra-high purity water $\left(18 \mathrm{M} \Omega \mathrm{cm}^{-1}\right)$ was obtained using a Milli-Q water purification system (Merck, Livingston, UK). Human plasma (pooled; Na EDTA anticoagulant; lot numbers 27079, IR07-081) (Innovative Research (Novi, MI, USA)) was purchased from Patricell (Nottingham, UK)). Pooled human liver microsomes (pHLM, donor pool 50, lots PL050E-A, PL050E-B with epidemiological information available for all donors $[110,111])$, pooled cryopreserved human hepatocytes (pHHeps, donor pool 50, lots HUE50-N, HUE50$\mathrm{P}$ with epidemiological information available for all donors [112,113]), Williams Media E (WME) (without glutamine or phenol red), cell maintenance supplement pack (with Cocktail B/Dexamethasone), trypan blue and cryopreserved hepatocyte recovery medium were purchased from Gibco (ThermoFisher Scientific, Waltham, MA, USA). pHLM preparations were incubated in a Stuart S160 benchtop incubator with shaking on a Stuart SSM1 mini orbital shaker (Cole-Parmer, St. Neots, UK). pHHep preparations were incubated in a Thermo Scientific HERAcell Vios $160 \mathrm{i} \mathrm{CO}_{2}$ incubator, with shaking on a Thermo Scientific $\mathrm{CO}_{2}$ resistant orbital shaker (Fisher Scientific, Loughborough, UK). Individual reference standard stock solutions were prepared at 1-10 mM in DMSO depending on purpose and stored at $-20{ }^{\circ} \mathrm{C}$ until use, unless used immediately. Working solutions were prepared on the day of use.

\subsection{Instrumentation}

Chromatographic hydrophobicity index (CHI) $\log$ D samples (see below) were analysed using high-performance liquid chromatography (HPLC) with a Shimadzu Nexera X2 HPLC coupled to a Shimadzu SPD-30 MA photodiode array detector (PDA) (Shimadzu, Kyoto, Japan). Data analysis was performed using Shimadzu LabSolutions 5.91 software. Samples $(2 \mu \mathrm{L})$ were injected onto an Acquity BEH $\mathrm{C}_{18}$ column $\left(2.1 \times 50 \mathrm{~mm}^{2}, 1.7 \mu \mathrm{m}\right)$ (Waters Corp., Milford, MA, USA) at a flow rate of $0.6 \mathrm{~mL} \mathrm{~min}{ }^{-1}$ at $25^{\circ} \mathrm{C}$. The sample chamber was maintained at $25{ }^{\circ} \mathrm{C}$. Gradient elution was performed, with mobile phase (MP) consisting of ammonium acetate in water $(10 \mathrm{mM}, \mathrm{pH} 7.4)(\mathrm{MP} \mathrm{A})$ and acetonitrile (MP B). The following gradient was used: 0-4.0 min from 5\% B to 95\% B, 4.0-4.5 min hold 95\% B, 4.5-4.51 min to 5\% B, 4.51-5.51 min hold 5\% B. Detection was achieved by scanning over a range of 190 to $500 \mathrm{~nm}$ wavelength, with $254 \mathrm{~nm}$ used for identification and peak area normalisation.

In vitro incubation samples (see below) were analysed using ultra-performance liquid chromatography-tandem mass spectrometry (UPLC-MS/MS) with a Waters Acquity UPLC coupled to a Waters Xevo TQ-S micro tandem mass spectrometer (Waters Corp., Milford, MA, USA). Data analysis was performed using Waters Masslynx 4.1 software (Waters Corp.). Samples $(1 \mu \mathrm{L})$ were injected onto an Acquity UPLC BEH C 18 column $\left(2.1 \times 50 \mathrm{~mm}^{2}, 1.7 \mu \mathrm{m}\right)$ (Waters Corp.) at a flow rate of $0.6 \mathrm{~mL} \mathrm{~min}^{-1}$ at $45^{\circ} \mathrm{C}$. The sample chamber was maintained at $4{ }^{\circ} \mathrm{C}$. Gradient elution was performed, with mobile phases (MP) consisting of water with formic acid (0.01\% v/v, MP A) and methanol with formic acid $(0.01 \% v / v, \mathrm{MP} \mathrm{B})$. The following gradient was used: $0-0.3 \mathrm{~min} 5 \% \mathrm{~B}, 0.3-1.3 \mathrm{~min}$ to $95 \%$ B, 1.3-1.79 min hold 95\% B, 1.79-1.8 min to 5\% B. MS acquisition was achieved with 
positive electrospray ionisation (ESI) and the MS operating in MRM mode, with MRM transitions provided in Section S1 of the supplementary information. The following MS parameters were used: source temperature $100{ }^{\circ} \mathrm{C}$, desolvation gas $500{ }^{\circ} \mathrm{C}$ at a flow rate of $1000 \mathrm{~L} \mathrm{~h}^{-1}$, cone gas flow rate $50 \mathrm{~L} \mathrm{~h}^{-1}$, collision gas (nitrogen) at $0.3 \mathrm{~mL} \mathrm{~min}{ }^{-1}$, cone voltage was $44 \mathrm{~V}$ and capillary voltage was $3.40 \mathrm{kV}$.

\subsection{In Silico Log P Prediction}

Log P values were predicted for all SCRAs tested in this study using multiple software packages, with the full dataset provided in Section S2 of the supplementary information. Software packages used were SwissADME (Swiss Institute of Bioinformatics, Lausanne, Switzerland; online and free to access), Gastroplus (SimulationPlus, Lancaster, CA, USA; MedChem Designer version 4.5), MoKa (Molecular Discovery, Borehamwood, UK; version 3.0), Canvas (Schrödinger, LLC, New York, NY, USA; version 3.6) and XlogP (Institute of Physical Chemistry, Peking University [114]).

\subsection{Experimental $\log D_{7.4}$}

Log $\mathrm{D}$ ( $\mathrm{pH}$ 7.4) was determined by chromatographic hydrophobicity index (CHI) measurements for the (S)-enantiomer of each SCRA involved in this study. A calibration mix of ten compounds at $10 \mu \mathrm{g} \mathrm{mL}^{-1}$ in 1:1 $(v / v)$ water:ACN was used (theophylline, phenyltetrazole, benzimidazole, colchicine, phenyltheophilline, acetophenone, indole, propiophenone, butyrophenone and valerophenone (all Sigma-Aldrich)). Test compounds were prepared at $0.25 \mathrm{mM}$ in 1:1 $(v / v)$ water:ACN. Samples $(n=2$ for calibration standards; $n=1$ for test compounds) were analysed using UPLC-PDA as described above. Retention times of calibration compounds are used to calculate retention factor $(\mathrm{k})$, which is plotted against literature $\mathrm{CHI}$ values for each compound. Linear regression was performed to obtain a line of best fit, from which the $\mathrm{CHI}$ and subsequently $\mathrm{CHI} \log \mathrm{D}$ of calibration and test compounds are calculated. Calculations used and calibration data from $\mathrm{CHI} \log \mathrm{D}$ studies are provided in Section S3 of the supplementary information.

\subsection{Plasma Stability Studies}

The pooled plasma used for both plasma stability and plasma binding studies originated from 50 donors, collected as whole blood from donors in the United States at an FDA-approved collection center, processed into plasma by centrifugation and immediately frozen (Innovative Research; Novi, MI, USA) and purchased from Patricell (Nottingham, UK). Plasma was tested by the manufacturers for a range of FDA-required viral markers. Pooled human plasma, was centrifuged $\left(3750 \mathrm{rpm}, 10 \mathrm{~min}, 22^{\circ} \mathrm{C}\right)$ and the supernatant buffered to $\mathrm{pH} 7.4$ by diluting to $70: 30$ plasma to potassium phosphate buffer ( $50 \mathrm{mM}$, $\mathrm{pH}$ 7.4). Stock solutions were prepared in DMSO. For inhibitor incubations, esterase inhibitors BNPP and PMSF were added to plasma mixture to give final concentrations of $500 \mu \mathrm{M}$ for each. For incubations without inhibitor an equivalent volume of DMSO was included. Plasma mixture was pre-incubated at $37^{\circ} \mathrm{C}$ for $5 \mathrm{~min}$. Test compounds $(5 \mu \mathrm{M})$ and procaine (positive control, $50 \mu \mathrm{M})$ were added to pre-warmed plasma mixture containing inhibitors. Incubation volume was $1 \mathrm{~mL}$. Samples were mixed and $80 \mu \mathrm{L}$ was immediately sampled and quenched into $200 \mu \mathrm{L}$ ACN spiked with donepezil (internal standard (IS), $50 \mathrm{ng} \mathrm{mL}^{-1}$ ). Plates were incubated at $37^{\circ} \mathrm{C}$ with shaking (100 rpm) and additional aliquots were sampled at 10, 30, 60, 120 and $180 \mathrm{~min}$. (S)-AMB-FUBINACA (1) was further sampled at 240 and $300 \mathrm{~min}$ as instability in plasma has been reported previously [63]. Samples were centrifuged $\left(3750 \mathrm{rpm}, 10 \mathrm{~min}, 22^{\circ} \mathrm{C}\right)$ and the supernatant $(150 \mu \mathrm{L})$ diluted with $50 \mu \mathrm{L}$ deionised water before analysis by UPLC-MS/MS. Peak area ratio of analyte to IS was used to determine half-lives of test compounds in plasma, both with and without the presence of esterase inhibitors. 


\subsection{Plasma Protein Binding}

Plasma protein binding was assessed by equilibrium dialysis in a 96-well dialysis block (HTDialysis, Ledyard, CT, USA). Dialysis membranes (12-14 kDa) were soaked in deionised water for at least $60 \mathrm{~min}$. Membranes were soaked overnight at $4{ }^{\circ} \mathrm{C}$ in ethanol:water 20:80\% $v / v$ and then rinsed with deionised water immediately prior to use. Pooled human plasma (Innovative Research, Novi, MI, USA) was centrifuged ( $3750 \mathrm{rpm}, 10 \mathrm{~min}, 22^{\circ} \mathrm{C}$ ), spiked with analyte at $10 \mu \mathrm{g} \mathrm{mL}{ }^{-1}$ and allowed to equilibrate at room temperature $\left(22^{\circ} \mathrm{C}\right)$ for $20 \mathrm{~min}$. Nicardipine and warfarin were included as positive controls. Spiked plasma $(150 \mu \mathrm{L})$ was dialysed against isotonic phosphate buffer $(\mathrm{pH} 7.4)(150 \mu \mathrm{L})$ for $5 \mathrm{~h}$ at $37^{\circ} \mathrm{C}$ with shaking at $100 \mathrm{rpm}$. Thermal degradation controls for each test compound were kept at $37^{\circ} \mathrm{C}$ and $4{ }^{\circ} \mathrm{C}$. Blank control plasma and buffer were included in the incubation. Following incubation, dialysed plasma samples and thermal degradation controls $(50 \mu \mathrm{L})$ were added to drug-free buffer $(50 \mu \mathrm{L})$, and dialysed buffer samples $(50 \mu \mathrm{L})$ were added to drug-free plasma $(50 \mu \mathrm{L})$. ACN $(200 \mu \mathrm{L})$ containing donepezil (IS, $\left.50 \mathrm{ng} \mathrm{mL}^{-1}\right)$ was added to each sample and samples were centrifuged $\left(3750 \mathrm{rpm}, 10 \mathrm{~min}, 22{ }^{\circ} \mathrm{C}\right)$. Supernatant $(150 \mu \mathrm{L})$ was added to $50 \mu \mathrm{L}$ deionised water and samples were analysed by UPLC-MS/MS as described above. Dialysed buffer from each well was tested for protein contamination using BCA protein assay reagent to determine whether membranes had been compromised. Percentage drug bound and fraction unbound were calculated as follows [115]:

$$
\% \text { bound }=\frac{(\mathrm{Pl}-\mathrm{Bu})}{\mathrm{Pl}} \times 100
$$

where $\mathrm{Pl}=$ Analyte $/ \mathrm{IS}$ ratio determined in plasma side

$\mathrm{Bu}=$ Analyte $/ \mathrm{IS}$ ratio determined in buffer side

$$
\text { Fraction unbound, } \mathrm{fu}=\frac{(100-\% \text { bound })}{100}
$$

\subsection{Metabolic Stability—Pooled Human Liver Microsome Incubations}

Test compounds and verapamil (positive control) were incubated at $0.5 \mu \mathrm{M}$ in pHLM $\left(0.5 \mathrm{mg}\right.$ microsomal protein $\left.\mathrm{mL}^{-1}\right)$ incubations. Total incubation volume was $500 \mu \mathrm{L}$. Procedure: Test compound working solutions $(50 \mu \mathrm{M}$ in potassium phosphate buffer ( $\mathrm{pH} 7.4)$ ) were prepared $(<1 \%$ DMSO). $\mathrm{pHLM}$ were thawed and diluted in potassium phosphate buffer $(\mathrm{pH} 7.4)$. Drug working solution $(5 \mu \mathrm{L})$ in phosphate buffer $(50 \mu \mathrm{M}$, final concentration $0.5 \mu \mathrm{M}$ ) and $445 \mu \mathrm{L}$ microsome suspension (final concentration $0.5 \mathrm{mg} \mathrm{mL}^{-1}$ ) were pre-incubated at $37^{\circ} \mathrm{C}$ for $5 \mathrm{~min}$, and $50 \mu \mathrm{L} 8 \mathrm{mg} \mathrm{mL}^{-1} \mathrm{NADPH}$ in phosphate buffer (final concentration $0.8 \mathrm{mg} \mathrm{mL}^{-1}$ ) was used to initiate the reaction. Plates were incubated at $37^{\circ} \mathrm{C}$ with shaking (100 rpm) and samples (50 $\mu \mathrm{L}$ ) collected at $0,3,6,9,15$, $30 \mathrm{~min}$. Reactions were quenched in $200 \mu \mathrm{L}$ ACN spiked with donepezil (IS, $50 \mathrm{ng} \mathrm{mL}^{-1}$ ). Samples were diluted with $50 \mu \mathrm{L}$ deionised water and sealed and centrifuged ( $3750 \mathrm{rpm}$, $10 \mathrm{~min}, 22^{\circ} \mathrm{C}$ ) to sediment any precipitated proteins. Samples were analysed by UPLCMS/MS in a 96 deep-well $2 \mathrm{~mL}$ plate. Each SCRA was incubated at least in triplicate but additional incubations were carried out across a number of analytical batches, giving greater replication and a greater understanding of system variability. Microsomal scaling factors used for human liver microsome incubations in the literature vary. Intrinsic clearance and predicted in vivo clearance rates calculated using alternative scaling factors found in the literature is provided in Section S6 of the supplementary information, to aid comparison of data between publications.

\subsection{Metabolic Stability—Pooled Human Cryopreserved Hepatocyte Incubations}

Test compounds and positive controls (verapamil, 7-ethoxycoumarin (7-EC) and 7hydroxycoumarin $(7-\mathrm{HC})$ ) were incubated at $0.5 \mu \mathrm{M}$ in pooled human cryopreserved hepatocytes (pHHeps, 50 donor pool, 0.25 million cells $\mathrm{mL}^{-1}$ ). Total incubation volume was $400 \mu \mathrm{L}$. Procedure: Cells were thawed and added to cryopreserved hepatocyte recovery 
media, centrifuged $\left(100 \times g, 10 \mathrm{~min}, 22^{\circ} \mathrm{C}\right)$, counted and diluted in WME $\left(37^{\circ} \mathrm{C}\right.$, bubbled with $\left.5 \% \mathrm{CO}_{2}: 95 \% \mathrm{O}_{2}\right)$. To initiate reactions, $200 \mu \mathrm{L}$ of drug working solution $(1 \mu \mathrm{M})$ was added to $200 \mu \mathrm{L}$ cell suspension ( 0.5 million cells $\left.\mathrm{mL}^{-1}\right)$. Samples were mixed and $20 \mu \mathrm{L}$

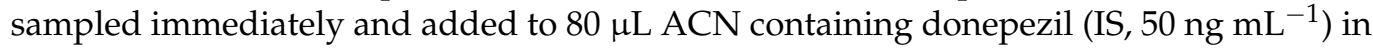
a 96 deep-well $2 \mathrm{~mL}$ plate. Plates were incubated at $37^{\circ} \mathrm{C}$ with $5 \% \mathrm{CO}_{2}$ with agitation at $95 \mathrm{rpm}$. Further aliquots were taken at 3, 6, 9, 15, 30, 45, $60 \mathrm{~min}$. Samples were diluted with $100 \mu \mathrm{L}$ of water/ACN (80:20 v/v) and centrifuged (2800 rpm, $\left.10 \mathrm{~min}, 22{ }^{\circ} \mathrm{C}\right)$ prior to UPLCMS/MS analysis. Each SCRA was incubated at least in triplicate but additional incubations were carried out across a number of analytical batches, giving greater replication and a greater understanding of system variability. Differing values for hepatocyte cell density are reported in the literature. Intrinsic clearance and predicted in vivo clearance rates calculated using an alternative hepatocyte cell density is provided in Section S7 of the supplementary information, to aid comparison of data between publications.

Rate constants $\left(k, \mathrm{~min}^{-1}\right)$ and half-lives $\left(\mathrm{t}_{1 / 2}\right)$ were calculated using XLfit 5.3.1 add-in (IDBS, Surrey, UK) for Microsoft Excel 2013, version 15.0 (Microsoft, Redmond, WA, US), calculated from plots of analyte/IS peak area ratio against time. Microsomal intrinsic clearance $\left(\mathrm{CL}_{\text {int micr }}\right)$ ( $\mathrm{pHLM}$ data) and intrinsic clearance $\left(\mathrm{CL}_{\mathrm{int}}\right)$ scaled to whole-liver dimensions for humans (pHLM and pHHeps data) were calculated from $k$, liver and body weight estimates and scaling factors $[13,96,116]$. Hepatic clearance $\left(\mathrm{CL}_{\mathrm{H}}\right)$ and extraction ratios $\left(\mathrm{E}_{\mathrm{H}}\right)$ were estimated based on the corresponding human $C L_{\text {int }}$ values, fraction unbound and estimates of liver blood flow rate (human $21 \mathrm{~mL} \mathrm{~min}^{-1} \mathrm{~kg}^{-1}$ ) $[96,117,118]$.

The equations used for in vitro intrinsic clearance calculations and human in vivo clearance estimation were as described by Baranczewski et al. (2006) [96], Rane, Wilkinson \& Shand (1977) [117] and Obach et al. (1997) [118] and are provided in Section S4 of the supplementary information.

\section{Conclusions}

Many pharmacokinetic studies on SCRAs investigate metabolite formation as an aid to toxicological analysis and interpretation. Determination of intrinsic clearance of SCRAs by pHLM is also relatively common. However, few investigate SCRA clearance by HHeps or account for other pharmacokinetic parameters such as plasma stability or protein binding, or compare the clearance rates for a range of SCRAs of closely related structural classes in the same study. Here, for the first time, human in vivo clearance predictions are provided for valinate and tert-leucinate indole- and indazole-3-carboxamide SCRAs based on experimentally derived PPB data and in vitro intrinsic clearance by both pHLM and pHHeps. These compounds are lipophilic and highly protein bound, and so the parent compounds of many may only be present in authentic urine samples in small proportions compared to their metabolites. The results presented here support reports that, although some of these compounds are relatively unstable in vitro, as they are highly plasma protein bound the parent drug is likely stored in the adipose tissue of chronic users and may be detectable for an extended duration in plasma and urine following redistribution.

Overall, the tested SCRAs were cleared rapidly in vitro in both pHLM and pHHeps; $(S)$ - enantiomers were cleared at a faster rate than $(R)$ - enantiomers, except for compounds containing an alkene tail group when incubated in pHLM. Between compounds, the head group of the molecule is the one of the most important rate-determining factors, with valine (dimethyl) methyl ester (AMB-) compounds cleared the fastest, followed by tert-leucine (trimethyl) methyl ester (MDMB-) compounds, and with valinamide (dimethyl) (AB-) compounds cleared at the overall slowest rate. Once PPB data were considered, predicted in vivo hepatic clearance rates were much slower than in vitro intrinsic clearance. Despite some observed differences in intrinsic clearance between enantiomers, once protein binding was accounted for predicted whole-body clearance rates and hepatic extraction ratios were comparable between enantiomers. Predicted in vivo rates however varied widely between compounds suggesting that these compounds will be present in the circulatory system for 
varied durations, and thus may have varied durations of action, creating uncertainty for users where the specific drug as well as dose present is unknown.

Supplementary Materials: The following are available online: Section S1: Table S1: Multiple reaction monitoring (MRM) transitions for tested synthetic cannabinoid receptor agonists. Section S2: Table S2: In silico Log P predictions using various software packages. Section S3: Equations and literature chromatographic hydrophobicity index data used in determining CHI Log D values, Table S3: Literature chromatographic hydrophobicity index $(\mathrm{CHI})$ values $\left(\mathrm{CHI}_{0}\right)$, Figure S1: Plot of retention factor $(\mathrm{k})$ against $\mathrm{CHI}_{0}$. Section S4: Equations used for in vitro intrinsic clearance calculation and human in vivo hepatic clearance estimation. Section S5: Figures S2-S20: Plasma stability study data. Section S6: Figures S21-S33: Graphical representation of intrinsic clearance data-human liver microsome incubations, Table S4-S30: Intrinsic clearance data-human liver microsome incubations. Section S7: Figures S34-S49: Graphical representation of intrinsic clearance data-human hepatocyte incubations, Table S31-S58: Intrinsic clearance data-human hepatocyte incubations.

Author Contributions: Conceptualization, A.M.B., K.D.R. and C.M.; methodology, A.M.B., O.E., J.R.; formal analysis, A.M.B., L.H.A. and J.R.; investigation, A.M.B. and L.H.A.; resources, L.H.A., K.D.R. and C.M.; data curation, A.M.B. and C.M.; writing—original draft preparation, A.M.B.; writingreview and editing, D.A.M., K.D.R. and C.M.; visualization, A.M.B. and C.M.; supervision, D.A.M., K.D.R. and CM.; project administration, C.M.; funding acquisition, C.M. All authors have read and agreed to the published version of the manuscript.

Funding: This research and the APC was funded by the Engineering and Physical Sciences Research Council (EPSRC) Doctoral Training Partnership, Grant Number EP/N509962/1. The Leverhulme Research Centre for Forensic Science (LRCFS) is funded by the Leverhulme Trust, Grant Number RC-2015-01.

Institutional Review Board Statement: Not applicable.

Informed Consent Statement: Not applicable.

Data Availability Statement: Data are available in a publicly accessible repository: Brandon, A.M.; Antonides, L.H.; Riley, J.; Epemolu, O.; Read, K.D.; McKenzie, C. 2021. Supporting data for “A Systematic Study of the In Vitro Pharmacokinetics and Estimated Human In Vivo Clearance of Indole and Indazole-3-Carboxamide Synthetic Cannabinoid Receptor Agonists Detected on the Illicit Drug Market"; available at doi:10.15132/10000164.

Acknowledgments: This study was funded by the Engineering and Physical Sciences Research Council Doctoral Training Partnership. Thank you to Caroline Peet for assistance with in silico log P predictions and to Karolina Wrobel for $\log \mathrm{D}_{7.4}$ data. Thanks to Darren Edwards and Yoko Shishikura for technical support and advice with UPLC analyses and to Nicole Mutter for providing knowledge and expertise on in vitro assays. We thank Henrik Gréen, Division of Drug Research, Department of Medical and Health Sciences, Linköping University, Linköping, Sweden and Department of Forensic Genetics and Forensic Toxicology, National Board of Forensic Medicine, Linköping, Sweden for his very helpful comments on earlier versions of this manuscript.

Conflicts of Interest: The authors declare no conflict of interest.

Sample Availability: Not applicable.

\section{References}

1. Antonides, L.H.; Cannaert, A.; Norman, C.; Vives, L.; Harrison, A.; Costello, A.; NicDaeid, N.; Stove, C.P.; Sutcliffe, O.B.; McKenzie, C. Enantiospecific synthethis, chiral separation, and biological activity of four indazole-3-carboxamide-type synthetic cannabinoid receptor agonists and their detection in seized drug samples. Front. Chem. 2019, 7, 321. [CrossRef]

2. Sachdev, S.; Vemuri, K.; Banister, S.D.; Longworth, M.; Kassiou, M.; Santiago, M.; Makriyannis, A.; Connor, M. In vitro determination of the efficacy of illicit synthetic cannabinoids at $\mathrm{CB}_{1}$ receptors. Br. J. Pharmacol. 2019, 176, 4653-4665. [CrossRef]

3. European Monitoring Centre for Drugs and Drug Addiction. European Drug Report 2019: Trends and Developments; Publications Office of the European Union: Luxembourg, 2020. Available online: https://www.emcdda.europa.eu/publications/edr/trendsdevelopments / 2019 (accessed on 1 November 2020).

4. Potts, A.J.; Cano, C.; Thomas, S.H.L.; Hill, S.L. Synthetic cannabinoid receptor agonists: Classification and nomenclature. Clin. Toxicol. 2020, 58, 82-98. [CrossRef] 
5. Luethi, D.; Liechti, M.E. Designer drugs: Mechanism of action and adverse effects. Arch. Toxicol. 2020, 94, 1085-1133. [CrossRef] [PubMed]

6. Giorgetti, A.; Busardò, F.P.; Tittarelli, R.; Auwärter, V.; Giorgetti, R. Post-mortem toxicology: A systematic review of death cases involving synthetic cannabinoid receptor agonists. Front. Psychiatry 2020, 11, 464. [CrossRef]

7. Trecki, J.; Gerona, R.R.; Schwartz, M.D. Synthetic cannabinoid-related illnesses and deaths. N. Engl. J. Med. 2015, $373,103-107$. [CrossRef]

8. Adams, A.J.; Banister, S.D.; Irizarry, L.; Trecki, J.; Schwartz, M.; Gerona, R. "Zombie” outbreak caused by the synthetic cannabinoid AMB-FUBINACA in New York. N. Engl. J. Med. 2017, 376, 235-242. [CrossRef] [PubMed]

9. Sherpa, D.; Paudel, B.M.; Subedi, B.H.; Chow, R.D. Synthetic cannabinoids: The multi-organ failure and metabolic derancements associated with getting high. J. Community Hosp. Intern. Med. Perspect. 2015, 5, 27540. [CrossRef] [PubMed]

10. Kolla, N.J.; Mishra, A. The endocannabinoid system, aggression, and the violence of synthetic cannabinoid use, borderline personality disorder, antisocial personality disorder, and other psychiatric disorders. Front. Behav. Neurosci. 2018, $12,41$. [CrossRef] [PubMed]

11. Oliveira da Cruz, J.F.; Ioannidou, C.; Zottola, A.C.P.; Muguruza, C.; Gomez-Sotres, P.; Fernandez, M.; Callado, L.F.; Marsicano, G.; Busquets-Garcia, A. Sex-dependent pharmacological profiles of the synthetic cannabinoid MMB-Fubinaca. Addict. Biol. 2020, e12940. [CrossRef]

12. Castaneto, M.S.; Wohlfarth, A.; Desrosiers, N.A.; Hartman, R.L.; Gorelick, D.A.; Huestis, M.A. Synthetic cannabinoids pharmacokinetics and detection methods in biological matrices. Drug Metab. Rev. 2015, 47, 124-174. [CrossRef]

13. Davidsen, A.B.; Mardal, M.; Linnet, K. In vitro metabolism and hepatic intrinsic clearance of the synthetic cannabinoid receptor agonist JWH-122 and its four $\omega$-halogenated analogues. AAPS J. 2019, 21, 1-9. [CrossRef]

14. Diao, X.; Wohlfarth, A.; Pang, S.; Scheidweiler, K.B.; Huestis, M.A. High-resolution mass spectrometry for characterizing the metabolism of synthetic cannabinoid THJ-018 and its 5-fluoro analog THJ-2201 after incubation in human hepatocytes. Clin. Chem. 2016, 62, 157-169. [CrossRef]

15. Kevin, R.C.; Lefever, T.W.; Snyder, R.W.; Patel, P.R.; Gamage, T.F.; Fennell, T.R.; Wiley, J.L.; McGregor, I.S.; Thomas, B.F. Kinetic and metabolic profiles of synthetic cannabinoids NNEI and MN-18. Drug Test. Anal. 2018, 10, 137-147. [CrossRef]

16. Wohlfarth, A.; Castaneto, M.S.; Zhu, M.; Pang, S.; Scheidweiler, K.B.; Kronstrand, R.; Huestis, M.A. Pentylindole/pentylindazole synthetic cannabinoids and their 5-fluoro analogs produce different primary metabolites: Metabolite profiling for AB-PINACA and 5F-AB-PINACA. AAPS J. 2015, 17, 660-677. [CrossRef]

17. Carlier, J.; Diao, X.; Wohlfarth, A.; Scheidweiler, K.; Huestis, M.A. In vitro metabolite profiling of ADB-FUBINACA, a new synthetic cannabinoid. Curr. Neuropharmacol. 2017, 15, 682-691. [CrossRef] [PubMed]

18. Hess, C.; Schoeder, C.T.; Pillaiyar, T.; Madea, B.; Müller, C.E. Pharmacological evaluation of synthetic cannabinoids identified as constituents of spice. Forensic Toxicol. 2016, 34, 329-343. [CrossRef]

19. Kakehashi, H.; Shima, N.; Ishikawa, A. Effects of lipophilicity and functional groups of synthetic cannabinoids on their blood concentrations and urinary excretion. Forensic Sci. Int. 2020, 307, 110106. [CrossRef] [PubMed]

20. Schaefer, N.; Kröll, A.K.; Körbel, C.; Laschke, M.W.; Menger, M.D.; Maurer, H.H.; Meyer, M.R.; Schmidt, P.H. Distribution of the (synthetic) cannabinoids JWH-210, RCS-4, as well as $\Delta$ 9-tetrahydrocannabinol following pulmonary administration to pigs. Arch. Toxicol. 2019, 93, 2211-2218. [CrossRef] [PubMed]

21. Saito, K.; Kokaji, Y.; Muranaka, Y.; Ito, R. Simultaneous determination of synthetic cannabinoids in illegal herbal products and blood by LC/TOF-MS, and linear regression analysis of retention time using log $\mathrm{P}_{\mathrm{ow}}$. Forensic Chem. 2020, 17, 100202. [CrossRef]

22. Norman, C.; Walker, G.; McKirdy, B.; McDonald, C.; Fletcher, D.; Antonides, L.H.; Sutcliffe, O.B.; NicDaéid, N.; McKenzie, C. Detection and quantitation of synthetic cannabinoid receptor agonists in infused papers from prisons in a constantly evolving illicit market. Drug Test. Anal. 2020, 12, 538-544. [CrossRef]

23. Schoeder, C.T.; Hess, C.; Madea, B.; Meiler, J.; Müller, C.E. Pharmacological evaluation of new constituents of "Spice": Synthetic cannabinoids based on indole, indazole, benzimidazole and carbazole scaffolds. Forensic Toxicol. 2018, 36, 385-403. [CrossRef]

24. Al-Matrouk, A.; Algallaf, M.; AlShemmeri, A.; BoJbarah, H. Identification of synthetic cannabinoids that were seized, consumed, or associated with deaths in Kuwait in 2018 using GC-MS and LC-MS-MS analysis. Forensic Sci. Int. 2019, 303, 109960. [CrossRef]

25. Somerville, R.F.; Hassan, V.R.; Kolbe, E.; Partington, H.K.; Walsh, K.A.J.; Kappatos, D.C.; Johnson, C.S. The identification and quantification of synthetic cannabinoids seized in New Zealand in 2017. Forensic Sci. Int. 2019, 300, 19-27. [CrossRef] [PubMed]

26. Seely, K.A.; Lapoint, J.; Moran, J.H.; Fattore, L. Spice drugs are more than harmless herbal blends: A review of the pharmacology and toxicology of synthetic cannabinoids. Prog. Neuropsychopharmacol. Biol. Psychiatry 2012, 39, 234-243. [CrossRef]

27. Münster-Müller, S.; Matzenbach, I.; Knepper, T.; Zimmermann, R.; Pütz, M. Profiling of synthesis-related impurities of the synthetic cannabinoid Cumyl-5F-PINACA in seized samples of e-liquids via multivariate analysis of UHPLC-MSn data. Drug Test. Anal. 2019, 12, 119-126. [CrossRef]

28. Peace, M.R.; Krakowiak, R.I.; Wolf, C.E.; Poklis, A.; Poklis, J.L. Identification of MDMB-FUBINACA in commercially available e-liquid formulations sold for use in electronic cigarettes. Forensic Sci. Int. 2017, 271, 92-97. [CrossRef]

29. Doi, T.; Asada, A.; Takeda, A.; Tagami, T.; Katagi, M.; Kamata, H.; Sawabe, Y. Enantioseparation of the carboxamide-type synthetic cannabinoids N-(1-amino-3-methyl-1-oxobutan-2-yl)-1-(5-fluoropentyl)-1H-indazole-3-carboxamide and methyl [1(5-fluoropentyl)-1H-indazole-3-carbonyl]-valinate in illicit herbal products. J. Chromatogr. A 2016, 1473, 83-89. [CrossRef] [PubMed] 
30. Doi, T.; Tagami, T.; Takeda, A.; Asada, A.; Sawabe, Y. Evaluation of carboxamide-type synthetic cannabinoids as $\mathrm{CB}_{1} / \mathrm{CB}_{2}$ receptor agonists: Difference between the enantiomers. Forensic Toxicol. 2018, 36, 51-60. [CrossRef] [PubMed]

31. Antonides, L.H.; Cannaert, A.; Norman, C.; NicDáeid, N.; Sutcliffe, O.B.; Stove, C.P.; McKenzie, C. Shape matters: The application of chiral profiling and activity based assays to the evaluation of synthetic cannabinoid receptor agonists in infused papers from prisons. Drug Test. Anal. 2020, 1-20. [CrossRef]

32. Millar, S.A.; Stone, N.L.; Yates, A.S.; O'Sullivan, S.E. A systematic review on the pharmacokinetics of cannabidiol in humans. Front. Pharmacol. 2018, 9, 1365. [CrossRef] [PubMed]

33. Huestis, M.A. Human cannabinoid pharmacokinetics. Chem. Biodivers. 2007, 4, 1770-1804. [CrossRef] [PubMed]

34. Ohlsson, A.; Lindgren, J.E.; Wahlen, A.; Agurell, S.; Hollister, L.E.; Gillespie, H.K. Plasma delta-9 tetrahydrocannabinol concentrations and clinical effects after oral and intravenous administration and smoking. Clin. Pharmacol. Ther. 1980, 28, 409-416. [CrossRef] [PubMed]

35. Huestis, M.A. Pharmacokinetics and metabolism of the plant cannabinoids, delta9-tetrahydrocannabinol, cannabidiol and cannabinol. Handb. Exp. Pharmacol. 2005, 168, 657-690. [CrossRef]

36. Grotenhermen, F. Pharmacokinetics and pharmacodynamics of cannabinoids. Clin. Pharmacokin. 2003, 42, 327-360. [CrossRef]

37. Franz, F.; Jechle, H.; Wilde, M.; Angerer, V.; Huppertz, L.M.; Longworth, M.; Kassiou, M.; Jung, M.; Auwärter, V. Structuremetabolism relationships of valine and tert-leucine-derived synthetic cannabinoid receptor agonists: A systematic comparison of the in vitro phase I metabolism using pooled human liver microsomes and high-resolution mass spectrometry. Forensic Toxicol. 2019, 37, 316-329. [CrossRef]

38. Diao, X.; Huestis, M.A. New synthetic cannabinoids metabolism and strategies to best identify optimal marker metabolites. Front. Chem. 2019, 7, 1-9. [CrossRef]

39. Schaefer, N.; Nordmeier, F.; Kröll, A.K.; Körbel, C.; Laschke, M.W.; Menger, M.D.; Maurer, H.H.; Meyer, M.R.; Schmidt, P.H. Is adipose tissue suitable for detection of (synthetic) cannabinoids? A comparative study analyzing antemortem and postmortem specimens following pulmonary administration of JWH-210, RCS-4, as well as $\Delta$ 9-tetrahydrocannabinol to pigs. Arch. Toxicol. 2020, 94, 3421-3431. [CrossRef] [PubMed]

40. Sharma, P.; Murthy, P.; Bharath, M.M.S. Chemistry, metabolism, and toxicology of cannabis: Clinical implications. Iran J Psychiatry 2012, 7, 149-156. [PubMed]

41. Saito, T.; Namera, A.; Miura, N.; Ohta, S.; Miyazaki, S.; Osawa, M.; Inokuchi, S. A fatal case of MAM-2201 poisoning. Forensic Toxicol. 2013, 31, 333-337. [CrossRef]

42. Sasaki, C.; Saito, T.; Shinozuka, T.; Irie, W.; Murakami, C.; Maeda, K.; Nakamaru, N.; Oishi, M.; Nakamura, S.; Kurihara, K. A case of death caused by abuse of a synthetic cannabinoid N-1-naphthalenyl-1-pentyl-1H-indole-3-carboxamide. Forensic Toxicol. 2014, 33, 165-169. [CrossRef]

43. Franz, F.; Haschimi, B.; King, L.A.; Auwärter, V. Extraordinary long detection window of a synthetic cannabinoid metabolite in human urine-Potential impact on therapeutic decisions. Drug Test. Anal. 2020, 12, 391-396. [CrossRef] [PubMed]

44. Mühlebach, S.; Wyss, P.A.; Bickel, M.H. Comparative adipose tissue kinetics of thiopental, DDE and 2,4,5,2',4',5'hexachlorobiphenyl in the rat. Xenobiotica 1985, 15, 485-491. [CrossRef]

45. Betschart, H.R.; Jondorf, W.R.; Bickel, M.H. Differences in adipose tissue distribution of basic lipophilic drugs between intraperitoneal and other routes of administration. Xenobiotica 1988, 18, 113-121. [CrossRef]

46. Moor, M.J.; Steiner, S.H.; Jachertz, G.; Bicker, M.H. Adipose tissue distribution and chemical structure of basic lipophilic drugs: Desipramine, $N$-acetyl desipramine, and haloperidol. Pharmacol. Toxicol. 1992, 70, 121-124. [CrossRef] [PubMed]

47. Bickel, M.H. The role of adipose tissue in the distribution and storage of drugs. Prog. Drug Res. 1984, 28, 273-303. [CrossRef]

48. Hutter, M.; Moosmann, B.; Kneisel, S.; Auwärter, V. Characteristics of the designer drug and synthetic cannabinoid receptor agonist AM-2201 regarding its chemistry and metabolism. J. Mass Spectrom. 2013, 48, 885-894. [CrossRef]

49. Toennes, S.W.; Geraths, A.; Pogoda, W.; Paulke, A.; Wunder, C.; Theunissen, E.L.; Ramaekers, J.G. Pharmacokinetic properties of the synthetic cannabinoid JWH-018 and of its metabolites in serum after inhalation. J. Pharm. Biomed. Anal. 2017, 140, $215-222$. [CrossRef] [PubMed]

50. Giorgetti, A.; Mogler, L.; Haschimi, B.; Halter, S.; Franz, F.; Westphal, F.; Fischmann, S.; Riedel, J.; Pütz, M.; Auwärter, V. Detection and phase I metabolism of the 7-azaindole-derived synthetic cannabinoid 5F-AB-P7AICA including a preliminary pharmacokinetic evaluation. Drug Test. Anal. 2020, 12, 78-91. [CrossRef]

51. Tai, S.; Fantegrossi, W.E. Pharmacological and toxicological effects of synthetic cannabinoids and their metabolites. Curr. Top. Behav. Neurosci. 2017, 32, 249-262. [CrossRef]

52. Tai, S.; Fantegrossi, W.E. Synthetic cannabinoids: Pharmacology, behavioral effects, and abuse potential. Curr. Addict. Rep. 2014, 1, 129-136. [CrossRef] [PubMed]

53. Finlay, D.B.; Manning, J.J.; Ibsen, M.S.; Macdonald, C.E.; Patel, M.; Javitch, J.A.; Banister, S.D.; Glass, M. Do toxic synthetic cannabinoid receptor agonists have signature in vitro activity profiles? A case study of AMB-FUBINACA. ACS Chem. Neurosci. 2019, 10, 4350-4360. [CrossRef]

54. Presley, B.C.; Castaneto, M.S.; Logan, B.K.; Jansen-Varnum, S.A. Metabolic profiling of synthetic cannabinoid 5F-ADB and identification of metabolites in authentic human blood samples via human liver microsome incubation and ultra-high performance liquid chromatography/high-resolution mass spectrometry. Rapid Commun. Mass Spectrom. 2020, 34, e8908. [CrossRef] 
55. Wagmann, L.; Frankenfeld, F.; Park, Y.M.; Herrmann, J.; Fischmann, S.; Westphal, F.; Müller, R.; Flockerzi, V.; Meyer, M.R. How to study the metabolism of new psychoactive substances for the purpose of toxicological screenings-A follow-up study comparing pooled human liver S9, HepaRG cells, and zebrafish larvae. Front. Chem. 2020, 8, 539. [CrossRef]

56. Watanabe, S.; Vikingsson, S.; Åstrand, A.; Gréen, H.; Kronstrand, R. Biotransformation of the new synthetic cannabinoid with an alkene, MDMB-4en-PINACA, by human hepatocytes, human liver microsomes, human urine and blood. AAPS J. 2020, 22, 1-9. [CrossRef] [PubMed]

57. Watanabe, S.; Wu, X.; Dahlen, J.; Konradsson, P.; Vikingsson, S.; Kronstrand, R.; Gréen, H. Metabolism of MMB022 and identification of dihydrodiol formation in vitro using synthesized standards. Drug Test. Anal. 2020, 12, 1432-1441. [CrossRef]

58. Obach, R.S. Cytochrome P450-catalyzed metabolism of ezlopitant alkene (CJ-12,458), a pharmacologically active metabolite of ezlopitant: Enzyme kinetics and mechanism of an alkene hydration reaction. Drug Metab. Dispos. 2001, 29, $1057-1067$.

59. De Costa, K.S.; Black, S.R.; Thomas, B.F.; Burgess, J.P.; Mathews, J.M. Metabolism and disposition of $\alpha$-methylstyrene in rats. Drug Metab. Dispos. 2001, 29, 166-171. [PubMed]

60. Presley, B.C.; Logan, B.K.; Jansen-Varnum, S.A. In vitro phase I metabolism of indazole carboxamide synthetic cannabinoid MDMB-CHMINACA via human liver microsome incubation and high-resolution mass spectrometry. Drug Test. Anal. 2019, 11, 1264-1276. [CrossRef]

61. Thomsen, R.; Nielsen, L.M.; Holm, N.B.; Rasmussen, H.B.; Linnet, K. Synthetic cannabimimetic agents metabolized by carboxylesterases. Drug Test. Anal. 2015, 7, 565-576. [CrossRef] [PubMed]

62. Kong, T.Y.; Kim, J.H.; Kim, D.K.; Lee, H.S. Synthetic cannabinoids are substrates and inhibitors of multiple drug-metabolizing enzymes. Arch. Pharm. Res. 2018, 41, 691-710. [CrossRef] [PubMed]

63. Krotulski, A.J.; Bishop-Freeman, S.C.; Mohr, A.L.A.; Logan, B.K. Evaluation of synthetic cannabinoid metabolites in human blood in the absence of parent compounds: A stability assessment. J. Anal. Toxicol. 2021, 45, 60-68. [CrossRef]

64. Kavanagh, P.; Grigoryev, A.; Krupina, N. Detection of metabolites of two synthetic cannabimimetics, MDMB-FUBINACA and ADB-FUBINACA, in authentic human urine specimens by accurate mass LC-MS: A comparison of intersecting metabolic patterns. Forensic Toxicol. 2017, 35, 284-300. [CrossRef]

65. Hess, C.; Krueger, L.; Unger, M.; Madea, B. Freeze-thaw stability and long-term stability of 84 synthetic cannabinoids in serum. Drug Test. Anal. 2017, 9, 1506-1511. [CrossRef]

66. Li, B.; Sedlacek, M.; Manoharan, I.; Boopathy, R.; Duysen, E.G.; Masson, P.; Lockridge, O. Butyrylcholinesterase, paraoxonase, and albumin esterase, but not carboxylesterase, are present in human plasma. Biochem. Pharmacol. 2015, 70, 1673-1684. [CrossRef] [PubMed]

67. Di, L. The impact of carboxylesterases in drug metabolism and pharmacokinetics. Curr. Drug Metab. 2018, 19, 91-102. [CrossRef]

68. Fu, J.; Pacyniak, E.; Leed, M.G.D.; Sadgrove, M.P.; Marson, L.; Jay, M. Interspecies differences in the metabolism of a multi-ester prodrug by carboxylesterases. J. Pharm. Sci. 2016, 105, 989-995. [CrossRef]

69. Castaneto, M.S.; Wohlfarth, A.; Pang, S.; Zhu, M.; Scheidweiler, K.B.; Kronstrand, R.; Huestis, M.A. Identification of ABFUBINACA metabolites in human hepatocytes and urine using high-resolution mass spectrometry. Forensic Toxicol. 2015, 33, 295-310. [CrossRef]

70. Mogler, L.; Franz, F.; Rentsch, D.; Angerer, V.; Weinfurtner, G.; Longworth, M.; Banister, S.D.; Kassiou, M.; Moosmann, B.; Auwärter, V. Detection of the recently emerged synthetic cannabinoid 5F-MDMB-PICA in 'legal high' products and human urine samples. Drug Test. Anal. 2017, 10, 196-205. [CrossRef] [PubMed]

71. Haschimi, B.; Mogler, L.; Halter, S.; Giorgetti, A.; Schwarze, B.; Westphal, F.; Fischmann, S.; Auwärter, V. Detection of the recently emerged synthetic cannabinoid 4F-MDMB-BINACA in "legal high" products and human urine specimens. Drug Test. Anal. 2019, 11, 1377-1386. [CrossRef]

72. Yeter, O.; Ozturk, Y.E. Metabolic profiling of synthetic cannabinoid 5F-ADB by human liver microsome incubations and urine samples using high-resolution mass spectrometry. Drug Test. Anal. 2018, 11, 847-858. [CrossRef] [PubMed]

73. Andersson, M.; Diao, X.; Wohlfarth, A.; Scheidweiler, K.B.; Huestis, M.A. Metabolic profiling of new synthetic cannabinoids AMB and 5F-AMB by human hepatocyte and liver microsome incubations and high-resolution mass spectrometry. Rapid Commun. Mass Spectrom. 2016, 30, 1067-1078. [CrossRef] [PubMed]

74. Hartman, D.A. Determination of the stability of drugs in plasma. Curr. Protoc. Pharmacol. 2003, 19, 7.6.1-7.6.8. [CrossRef]

75. Cyprotex. Plasma Stability Assay Product Sheet. 2020. Available online: https://www.cyprotex.com/product_sheets/Cyprotex_ Plasma_Stability_Product_Sheet.pdf (accessed on 3 June 2020).

76. Presley, B.C.; Castaneto, M.S.; Logan, B.K.; Jansen-Varnum, S.A. Assessment of synthetic cannabinoid FUB-AMB and its ester hydrolysis metabolite in human liver microsomes and human blood samples by UHPLC-MS/MS. Biomed. Chrom. 2020, 34 , e4884. [CrossRef]

77. Sands, C.D.; Chan, E.S.; Welty, T.E. Revisiting the significance of warfarin protein-binding displacement interactions. Ann. Pharmacother. 2002, 36, 1642-1644. [CrossRef]

78. Nguyen, L.P.; Gerstein, N.S. Cardiovascular Pharmacology in Noncardiac Surgery. In Essentials of Cardiac Anesthesia for Noncardiac Surgery; Kaplan, J.A., Cronin, B., Maus, T.M., Eds.; Elsevier: Amsterdam, The Netherlands, 2019. [CrossRef]

79. Miller, R.R.; Madeira, M.; Wood, H.B.; Geissler, W.M.; Raab, C.E.; Martin, I.J. Integrating the impact of lipophilicity on potency and pharmacokinetic parameters enables the use of diverse chemical space during small molecule drug optimization. J. Med. Chem. 2020, 63, 12156-12170. [CrossRef] 
80. Di, L.; Umland, J.P.; Trapa, P.E.; Maurer, T.S. Impact of recovery on fraction unbound using equilibrium dialysis. J. Pharm. Sci. 2012, 101, 1327-1335. [CrossRef]

81. Coleman, M.D. Factors Affecting Drug Metabolism. In Human Drug Metabolism: An Introduction; Coleman, M.D., Ed.; John Wiley \& Sons: Hoboken, NJ, USA, 2010. [CrossRef]

82. Stringer, R.; Nicklin, P.L.; Houston, J.B. Reliability of human cryopreserved hepatocytes and liver microsomes as in vitro systems to predict metabolomic clearance. Xenobiotica 2008, 38, 1313-1329. [CrossRef] [PubMed]

83. McGinnity, D.F.; Soars, M.G.; Urbanowicz, R.A.; Riley, R.J. Evaluation of fresh and cryopreserved hepatocytes as in vitro drug metabolism tools for the prediction of metabolic clearance. Drug Metab. Dispos. 2004, 32, 1247-1253. [CrossRef]

84. Lau, Y.Y.; Sapidou, E.; Cui, X.; White, R.E.; Cheng, K.C. Development of a novel in vitro model to predict hepatic clearance using fresh, cryopreserved, and sandwich-cultured hepatocytes. Drug Metab. Dispos. 2002, 30, 1446-1454. [CrossRef] [PubMed]

85. Riley, R.J.; McGinnity, D.F.; Austin, R.P. A unified model for predicting human hepatic, metabolic clearance from in vitro intrinsic clearance data in hepatocytes and microsomes. Drug Metab. Dispos. 2005, 33, 1304-1311. [CrossRef]

86. Wood, F.L.; Houston, J.B.; Hallifax, D. Clearance prediction methodology needs fundamental improvement: Trends common to rat and human hepatocytes/microsomes and implications for experimental methodology. Drug Metab. Dispos. 2017, 45, 1178-1188. [CrossRef]

87. Erratico, C.; Negreira, N.; Norouzizadeh, H.; Covaci, A.; Neels, H.; Maudens, K.; van Nuijs, A.L. In vitro and in vivo human metabolism of the synthetic cannabinoid AB-CHMINACA. Drug Test. Anal. 2015, 7, 866-876. [CrossRef]

88. Shen, Z.; Lv, C.; Zeng, S. Significance and challenges of stereoselectivity assessing methods in drug metabolism. J. Pharm. Anal. 2016, 6, 1-10. [CrossRef] [PubMed]

89. Di, L.; Keefer, C.; Scott, D.O.; Strelevitz, T.J.; Chang, G.; Bi, Y.A.; Lai, Y.; Duckworth, J.; Fenner, K.; Troutman, M.D.; et al. Mechanistic insights from comparing intrinsic clearance values between human liver microsomes and hepatocytes to guide drug design. Eur. J. Med. Chem. 2012, 57, 441-448. [CrossRef] [PubMed]

90. Truver, M.T.; Watanabe, S.; Åstrand, A.; Vikingsson, S.; Green, H.; Swortwood, M.J.; Kronstrand, R. 5F-MDMB-PICA metabolite identification and cannabinoid receptor activity. Drug Test. Anal. 2020, 12, 127-135. [CrossRef]

91. Wang, D.; Zou, L.; Jin, Q.; Hou, J.; Ge, G.; Yang, L. Human carboxylesterases: A comprehensive review. Acta Pharm. Sin. B. 2018, 8, 699-712. [CrossRef] [PubMed]

92. Kilford, P.J.; Gertz, M.; Houston, J.B.; Galetin, A. Hepatocellular binding of drugs: Correction for unbound fraction in hepatocyte incubations using microsomal binding or drug lipophilicity data. Drug Metab. Dispos. 2008, 36, 1194-1197. [CrossRef]

93. Hallifax, D.; Houston, J.B. Binding of drugs to hepatic microsomes: Comment and assessment of current prediction methodology with recommendation for improvement. Drug Metab. Dispos. 2006, 34, 724-726. [CrossRef]

94. Ménochet, K.; Kenworthy, K.E.; Houston, J.B.; Galetin, A. Use of mechanistic modeling to assess interindividual variability and interspecies differences in active uptake in human and rat hepatocytes. Drug Metabol. Dispos. 2012, 40, 1744-1756. [CrossRef]

95. Kevin, R.C.; Lefever, T.W.; Snyder, R.W.; Patel, P.R.; Fennell, T.R.; Wiley, J.L.; McGregor, I.S.; Thomas, B.F. In vitro and in vivo pharmacokinetics and metabolism of synthetic cannabinoids CUMYL-PICA and 5F-CUMYL-PICA. Forensic Toxicol. 2017, 35, 333-347. [CrossRef]

96. Baranczewski, P.; Stanczak, A.; Sundberg, K.; Svensson, R.; Wallin, A.; Jansson, J.; Garberg, P.; Postlind, H. Introduction to in vitro estimation of metabolic stability and drug interactions of new chemical entities in drug discovery and development. Pharmacol. Rep. 2006, 58, 453-472. [PubMed]

97. Diao, X.; Scheidweiler, K.B.; Wohlfarth, A.; Pang, S.; Kronstrand, R.; Huestis, M.A. In vitro and in vivo human metabolism of synthetic cannabinoids FDU-PB-22 and FUB-PB-22. AAPS J. 2016, 18, 455-464. [CrossRef] [PubMed]

98. Hasegawa, K.; Wurita, A.; Minakata, K.; Gonmori, K.; Nozawa, H.; Yamagishi, I.; Watanabe, K.; Suzuki, O. Postmortem distribution of AB-CHMINACA, 5-fluoro-AMB, and diphenidine in body fluids and solid tissues in a fatal poisoning case: Usefulness of adipose tissue for detection of the drugs in unchanged forms. Forensic Toxicol. 2015, 33, 45-53. [CrossRef]

99. Kneisel, S.; Teske, J.; Auwärter, V. Analysis of synthetic cannabinoids in abstinence control: Long drug detection windows in serum and implications for practitioners. Drug Test. Anal. 2014, 6, 135-136. [CrossRef] [PubMed]

100. Gottardo, R.; Bertaso, A.; Pascali, J.; Sorio, D.; Musile, G.; Trapani, E.; Seri, C.; Serpelloni, G.; Tagliaro, F. Micellar electrokinetic chromatography: A new simple tool for the analysis of synthetic cannabinoids in herbal blends and for the rapid estimation of their log P values. J. Chromatgr. A 2012, 1267, 198-205. [CrossRef]

101. Schaefer, N.; Kettner, M.; Laschke, M.W.; Schaefer, N.; Kettner, M.; Laschke, M.W.; Schlote, J.; Ewald, A.H.; Menger, M.D.; Maurer, H.H.; et al. Distribution of synthetic cannabinoids JWH-210, RCS-4 and $\Delta$ 9-tetrahydrocannabinol after intravenous administration to pigs. Curr. Neuropharmacol. 2017, 15, 713-723. [CrossRef]

102. Laizure, S.C.; Herring, V.; Hu, Z.; Witbrodt, K.; Parker, R.B. The role of human carboxylesterases in drug metabolism: Have we overlooked their importance? J. Hum. Pharmacol. Drug Ther. 2013, 33, 210-222. [CrossRef] [PubMed]

103. Zhang, J.Y.; Wang, Y.; Prakash, C. Xenobiotic-metabolizing enzymes in human lung. Curr. Drug Metab. 2006, 7, 939-948. [CrossRef] [PubMed]

104. Somers, G.I.; Lindsay, N.; Lowdon, B.M.; Jones, A.E.; Freathy, C.; Ho, S.; Woodrooffe, A.J.; Bayliss, M.K.; Manchee, G.R. A comparison of the expression and metabolizing activities of phase I and II enzymes in freshly isolated human lung parenchymal cells and cryopreserved human hepatocytes. Drug Metab. Dispos. 2007, 35, 1797-1805. [CrossRef] 
105. Watanabe, S.; Kuzhiumparambil, U.; Shanlin, F. In vitro metabolism of synthetic cannabinoid AM1220 by human liver microsomes and Cunninghamella elegans using liquid chromatography coupled with high resolution mass spectrometry. Forensic Toxicol. 2018, 36, 435-446. [CrossRef]

106. Diao, X.; Carlier, J.; Zhu, M.; Pang, S.; Kronstrand, R.; Scheidweiler, K.B.; Huestis, M.A. In vitro and in vivo human metabolism of a new synthetic cannabinoid NM-2201 (CBL-2201). Forensic Toxicol. 2017, 35, 20-32. [CrossRef] [PubMed]

107. Diao, X.; Scheidweiler, K.B.; Wohlfarth, A.; Zhu, M.; Pang, S.; Huestis, M.A. Strategies to distinguish new synthetic cannabinoid FUBIMINA (BIM-2201) intake from its isomer THJ-2201: Metabolism of FUBIMINA in human hepatocytes. Forensic Toxicol. 2016, 34, 256-267. [CrossRef] [PubMed]

108. Gandhi, A.S.; Wohlfarth, A.; Zhu, M.; Pang, S.; Castaneto, M.; Scheidweiler, K.B.; Huestis, M.A. High-resolution mass spectrometric metabolite profiling of a novel synthetic designer drug, $N$-(adamantan-1-yl)-1-(5-fluoropentyl)-1H-indole-3-carboxamide (STS-135), using cryopreserved human hepatocytes and assessment of metabolic stability with human liver microsomes. Drug Test. Anal. 2015, 7, 187-198. [CrossRef]

109. Cooman, T.; Bell, S. In vitro metabolism of the synthetic cannabinoids PX-1, PX-2, and PX-3 by high-resolution mass spectrometry and their clearance rates in human liver microsomes. Rapid Commun. Mass Spec. 2019, 33, 1816-1825. [CrossRef]

110. ThermoFisher Scientific. Certificate of Analysis: Pooled Human Liver Microsomes, Lot Number PL050E-A. 2019. Available online: https://www.thermofisher.com/document-connect/document-connect.html?url=https $\% 3 \mathrm{~A} \% 2 \mathrm{~F} \% 2 \mathrm{Fassets}$. thermofisher.com\%2FTFS-Assets\%2FLSG\%2Fcertificate\%2FCertificates-of-Analysis\%2FHMMCPL\%2520PL050E-A.pdf\&title= UEwwNTBFLUE= (accessed on 25 February 2021).

111. ThermoFisher Scientific. Certificate of Analysis: Pooled Human Liver Microsomes, Lot Number PL050E-B. 2019. Available online: https://www.thermofisher.com/document-connect/document-connect.html?url=https $\% 3 \mathrm{~A} \% 2 \mathrm{~F} \% 2 \mathrm{Fassets}$. thermofisher.com\%2FTFS-Assets\%2FLSG\%2Fcertificate\%2FCertificates-of-Analysis\%2FHMMCPL\%2520PL050E-B.pdf\&title= UEwwNTBFLUI= (accessed on 25 February 2021).

112. ThermoFisher Scientific. Certificate of Analysis: Primary Human Hepatocytes Cryopreserved Suspension, Lot Number HUE50-N. 2016. Available online: https://www.thermofisher.com/document-connect/document-connect.html?url=https $\% 3 \mathrm{~A} \% 2 \mathrm{~F} \%$ 2Fassets.thermofisher.com\%2FTFS-Assets $\% 2$ FLSG\%2Fcertificate $\% 2$ FCertificates $\% 2520$ of $\% 2520$ Analysis $\% 2 F H u e 50$ N_HMCS50 pdf\&title=SHVINTBO (accessed on 25 February 2021).

113. ThermoFisher Scientific. Certificate of Analysis: Primary Human Hepatocytes Cryopreserved Suspension, Lot Number HUE50-P. 2020. Available online: https://www.thermofisher.com/document-connect/document-connect.html?url=https $\% 3 \mathrm{~A} \% 2 \mathrm{~F} \%$ 2Fassets.thermofisher.com $\% 2 F T F S-A s s e t s \% 2 F L S G \% 2 F c e r t i f i c a t e \% 2 F C e r t i f i c a t e s-o f-A n a l y s i s \% 2 F H M C S 50 \% 2520 H U E 50-P$. pdf\&title=SFVFNTAtUA== (accessed on 25 February 2021).

114. Wang, R.; Fu, Y.; Lai, L. A new atom-additive method for calculating partition coefficients. J. Chem. Inf. Comp. Sci. 1997, 37, 615-621. [CrossRef]

115. Manchester, K.R.; Maskell, P.D.; Waters, L. Experimental versus theoretical $\log \mathrm{D}_{7.4}, \mathrm{pK}$ a and plasma protein binding values for benzodiazepines appearing as new psychoactive substances. Drug Test. Anal. 2018, 10, 1258-1269. [CrossRef]

116. Obach, R.S.; Baxter, J.G.; Liston, T.E.; Silber, B.M.; Jones, B.C.; MacIntyre, F.; Range, D.J.; Wastall, P. The prediction of human pharmacokinetic parameters from preclinical and in vitro metabolism data. J. Pharmacol. Exp. Ther. 1997, $283,46-58$.

117. Rane, A.; Wilkinson, G.R.; Shand, D.G. Prediction of hepatic extraction ratio from in vitro measurement of intrinsic clearance. J. Pharmacol. Exp. Ther. 1977, 200, 420-424. [PubMed]

118. Obach, R.S. Prediction of human clearance of twenty-nine drugs from hepatic microsomal intrinsic clearance data- an examination of in vitro half-life approach and nonspecific binding to microsomes. Drug Metab. Dispos. 1999, 27, 1350-1359. 